\title{
Trabecular bone structure parameters from 3D image processing of clinical multi-slice and cone-beam computed tomography data
}

\author{
Eva Klintström, Örjan Smedby, Rodrigo Moreno and Torkel Brismar
}

\section{Linköping University Post Print}

\section{Tweet}

N.B.: When citing this work, cite the original article.

The original publication is available at www.springerlink.com:

Eva Klintström, Örjan Smedby, Rodrigo Moreno and Torkel Brismar, Trabecular bone structure parameters from 3D image processing of clinical multi-slice and cone-beam computed tomography data, 2014, Skeletal Radiology, (43), 2, 197-204.

http://dx.doi.org/10.1007/s00256-013-1766-5

Copyright: Springer Verlag (Germany) http://www.springerlink.com/?MUD=MP

Postprint available at: Linköping University Electronic Press http://urn.kb.se/resolve?urn=urn:nbn:se:liu:diva-102880 


\section{Skeletal Radiology \\ Trabecular bone structure parameters from 3D image processing of clinical multi-slice and cone-beam computed tomography data}

\section{--Manuscript Draft--}

Manuscript Number:

Full Title:

Article Type:

Keywords:

Corresponding Author:
SKRA-D-13-00571R1

Trabecular bone structure parameters from 3D image processing of clinical multi-slice and cone-beam computed tomography data

Scientific Article

trabecular bone structure; cone-beam computed tomography; micro computed tomography; multi-slice computed tomography; bone segmentation

Eva Klintström, DDS

Linköping, SWEDEN

\section{Corresponding Author Secondary}

Information:

\section{Corresponding Author's Institution:}

\section{Corresponding Author's Secondary}

Institution:

\section{First Author:}

First Author Secondary Information:

Order of Authors:

$$
\begin{aligned}
& \hline \text { Eva Klintström, DDS } \\
& \text { Örjan Smedby, Professor } \\
& \hline \text { Rodrigo Moreno, PhD } \\
& \hline \text { Torkel Brismar, Professor }
\end{aligned}
$$

\section{Order of Authors Secondary Information:}

Abstract:
Objective. Bone strength depends on both mineral content and bone structure. The aim of this in vitro study was to develop a method for quantitative assessment of trabecular bone structure by applying three-dimensional image processing to data acquired with multi-slice and cone-beam computed tomography using micro-computed tomography as reference.

Material and Methods. 15 bone samples from the radius were examined. After segmentation, quantitative measures of bone volume, trabecular thickness, trabecular separation, trabecular number, trabecular nodes and trabecular termini were obtained.

Results. Both clinical machines overestimated bone volume and trabecular thickness and underestimated trabecular nodes and number but cone-beam CT to a lesser extent. Parameters obtained from cone beam CT were strongly correlated to $\mu \mathrm{CT}$, with correlation coefficients between 0.93 and 0.98 for all parameters except trabecular termini.

Conclusions. The high correlation between cone-beam CT and micro-CT suggest the possibility to quantify and monitor changes of trabecular bone microarchitecture in vivo using cone beam CT. 


\section{Revision Note}

This document gives a point-by-point response to the comments made by the Reviewers. Most of these comments have led to changes in the manuscript. In order to facilitate the task for the Editor and the Reviewers, the changes are marked with Reviewer 1 or Reviewer 2 with the following subtitles.

\section{Comment:}

\section{Response:}

\section{Changes:}

Proposed changes from the Reviewers in italics.

In this document we have noted Page $X X$ and Line $X X$, were to find the changes in the manuscript.

\section{Comment about weakness in the study:}

Weaknesses: Small sample population may affect study power. Unfortunately no a priori power analysis has been performed; it may be worth to include it (post-hoc).

\section{Response:}

We agree that for planning the current study it might have been wise to perform power calculations. With the high correlation coefficients obtained for CBCT ( 0.73 and above), post-hoc power calculations yield power estimates of at least $95 \%$ for all studied parameters (exact distribution, onetailed test, alpha=0.05). However in this study, we think that the relevant research question is not whether there is a positive correlation, but how strong the (expected) correlation is. This is the main reason for including confidence intervals rather than $p$ values in Table 3 . In accordance with this, we find it less relevant to include power calculation post hoc. 


\section{Reviewer 1}

\section{Comment 1:}

It may be worth to include "Cone Beam Computed Tomography" in the title. CBCT is presently a topic of interest and it may appeal to the readers, focusing their attention on this paper, especially due to the study conclusion

\section{Response:}

We agree with the reviewer and $\mathrm{CBCT}$ is now included in the title

\section{Changes:}

The new title is:

Trabecular bone structure parameters from 3D image processing of clinical multi-slice and cone-beam computed tomography data

\section{Comment 2:}

Introduction: Page 5 Line 16: Consider adding the following reference: Boutry $N$, Cortet $B$, Dubois $P$, Marchandise $X$, Cotten A. Trabecular bone structure of the calcaneus: preliminary in vivo MR imaging assessment in men with osteoporosis. Radiology. 2003 PubMed PMID:12676974.

\section{Response:}

We absolutely agree that MRI studies of trabecular bone structure is interesting to add to the article.

\section{Changes:}

The recommended article as well as text describing trabecular bone structure by MRI is now included in the Introduction. Page 1, line 17-20.

\section{Comment 3:}

Introduction: Page 5 Line 34: Consider adding the following reference: Phan CM, Macklin EA, Bredella MA, Dadrich M, Flechsig P, Yoo AJ, Hirsch JA, Gupta R. Trabecular structure analysis using C-arm CT: comparison with MDCT and flat-panel volume CT. Skeletal Radiol. 2011 PubMed PMID: 20658286.

\section{Response:}

The proposed article is interesting. However, we think that including it in this paper is not relevant since we are not describing any use of C-arm CT in the paper.

\section{Comment 4:}

M\&M: Page 6 Line 22: Consider condensing Fig. 1 a to f, in a single mosaic-image, with a single explanatory legend describing each single image.

\section{Response:}

We agree that it could be easier to read if we make the legend more explanatory. 


\section{Changes:}

We have now used a more descriptive legend for the images allowing them to be inserted as a single mosaic-image. See Legend to Fig. 1 a-f.

Material and Methods page 2 line 20.

\section{Comment 5 and 6:}

M\&M: Page 6 Line 40: As described the ARG algorithm has been performed, it may be worth to describe the hardware used to perform the analysis in order to allow method reproducibility.

M\&M: Page 6 Line 49: Consider describing the specific hardware used to perform the MATLAB analysis, in order to allow method reproducibility.

\section{Response:}

We agree with both comments.

\section{Changes:}

The hardware and the software used are now described in Material and Methods as follows: The MATLAB code used for segmenting the images was developed in house. The computer used was a standard PC with Intel Core i5, CPU at 2.60GHz, 4GB of RAM and 64-bit operating system. Material and Method. Page 2 line 46-49.

\section{Comment 7:}

Discussion and Conclusion: Page 9 Line 30: "Our measurements describing Tb.N, Tb.Th as well as Th.Sp are in good agreement with other studies indicating that the results are credible"...Please reference those studies.

\section{Response:}

We agree the need for references and the references below are included in the discussion.

\section{Changes:}

We have now included the following references in the discussion in the article:

The effect of voxel size on high-resolution peripheral computed tomography measurements of trabecular and cortical bone microstructure. Tjong W, Kazakia GJ, Burghardt AJ, Majumdar S. Med Variations in morphological and biomechanical indices at the distal radius in subjects with identical BMD. Kazakia GJ, Burghardt AJ, Link TM, Majumdar S. J Biomech. 2011 Jan 11;44(2):257-66.

Discussion. Page 5 line 31. 


\section{Comment 8:}

Discussion and Conclusion: Page 9 Line 47: Consider including the following reference: Koskinen SK, Haapamäki VV, Salo J, Lindfors NC, Kortesniemi M, Seppälä L,Mattila KT. CT arthrography of the wrist using a novel, mobile, dedicatedextremity cone-beam CT (CBCT). Skeletal Radiol. 2013 PubMed PMID: 22990597

\section{Response:}

We agree that the reference is important to include in the discussion.

\section{Changes:}

The reference is now included in the discussion as reference [30].

Discussion. Page 5 line 44. 


\section{Reviewer 2}

\section{Comment 1:}

Abstract. "The clinical machines grossly overestimated bone volume and trabecular thickness. Trabecular nodes and number were underestimated. "This seems to tell only one side of the story, looking at figures 4 and 5 it is clear that the overestimation and underestimations happens also for the CBCT method. A less biased sentence would be something like:

both machines overestimate bone volume and trabecular thickness and underestimate trabecular nodes and number, but CBCT to a lesser extent

\section{Response:}

We agree with the reviewer.

\section{Changes:}

We have changed the text in accordance with the comments from the reviewer.

New text: Both clinical machines overestimated bone volume and trabecular thickness and underestimated trabecular nodes and number, but cone-beam $\mathrm{CT}$ to a lesser extent.

\section{Comment 2:}

Introduction. Lines 16-23 the authors omit the current in vivo clinical use of high resolution MRI to quantify trabecular bone architecture, used for at least the past 15 years, and it has obvious advantages. Also HR-QPCT could be mentioned here, since this is already used in vivo with very good results. There is no need to omit these to elevate the potential and novelty of CBCT.

\section{Response:}

We agree that MRI is an important method for describing bone structure and have now added a discussion of the matter in the Discussion. In addition, both MRI and HR-pQCT are mentioned in the Introduction with appropriate references [8-12].

\section{Changes:}

In the Discussion: page 5 line 15-18, and in the Introduction: page 1 line 17-20.

\section{Comment 3.:}

Introduction. Line 25 "MSCT" I did not find an early definition, should be: multislice CT (MSCT)

\section{Changes:}

The change has been done.

Introduction: page 1 line 23 


\section{Comment 4:}

Materials and methods. Image processing: lines 33-34, it is not clear how the voxels are averaged and why, it is perfectly possible and common to do reconstructions with non isometric voxels.

\section{Response:}

We agree with the reviewer that the article benefits from more explanation in this matter.

\section{Changes:}

We have made explanatory changes in Material and Methods on page 2 line 35-39.

\section{Comment 5:}

Materials and methods. Lines 41-45 "The image processing is then repeated with a higher threshold and the procedure is iterated a segmentation, that was used to calculate the parameters, was defined as the iteration where the assessment function attained its minimum. "Should be: The image processing is then repeated with a higher threshold and the procedure is iterated. A segmentation, that was used to calculate the parameters, was defined as the iteration where the assessment function attained its minimum."

\section{Changes:}

We agree with the reviewer and the typo has been corrected.

Material and Methods page 2 line 41.

\section{Comment 6:}

Also it is not clear here if the segmentation was performed with a commercial package or with in house software (i.e. written in Matlab), please clarify.

\section{Changes:}

We have made changes in the text also in accordance with Reviewer 1 - Comment 5.

Material \& Methods Page 2 line 46-49.

\section{Comment 7:}

Discussion. Again no mention of high-resolution MR imaging, diffusion MR imaging and in-vivo MR spectroscopy tehniques.

\section{Response:}

We agree with the reviewer about the importance to include MRI in the article. In accordance with 
Comment 2 from Reviewer 2 and also in accordance with Comment 2 from Reviewer 1 we have made changes.

\section{Changes:}

References [8-10) is included in the Introduction page 1 line 17-18. Reference [10] is discussed in the Discussion page 6 line 17.

\section{Comment 8}

Discussion. Since there was an effect based on the filter used (e.g. bone) and exhaustive analysis of these seems warranted for the clinical machines. And it should have been included for at least on sample in this study.

\section{Response:}

For the GE machine we have used two different filters: Bone and bone plus. The effect of the filters are analyzed and described in the text and in the tables. We have also added a comment on this paragraph in the Discussion.

\section{Changes:}

New text added in the Discussion page 5 line 7-11.

\section{Comment 9:}

Discussion. The time required for the scan combined with motion artifacts in vivo at micron level resolutions seem to be quite a big obstacle for the application of this method in vivo, also the extention to other parts of the body seems very difficult.

\section{Response:}

The issue of the acquisition time is certainly critical for in vivo studies and are discussed in the Discussion page 5 line 34-35. 


\title{
Trabecular bone structure parameters from 3D image processing of clinical multi-slice and cone-beam computed tomography data
}

\author{
Authors: \\ Eva Klintström; DDS ${ }^{1,3}$ \\ Örjan Smedby; Professor 1,3 \\ Rodrigo Moreno; PhD ${ }^{1,4}$ \\ Torkel Brismar; Associate Professor ${ }^{2}$
}

\section{Affiliations:}

1 Center for Medical Image Science and Visualization (CMIV), Linköping University, Linköping, Sweden

2 Department of Clinical Science, Intervention and Technology at Karolinska Institutet and Department of Radiology, Karolinska University Hospital in Huddinge, Stockholm, Sweden 3 Department of Medical and Health Sciences (IMH) and Radiology, Linköping University and Department of Radiology, UHL County Council of Östergötland, Linköping, Sweden 4 Department of Medical and Health Sciences (IMH) and Radiology, Linköping University. Linköping, Sweden

\section{Email:}

Eva Klintström; $\quad$ eva.klintstrom@lio.se

Örjan Smedby; $\quad$ orjan.smedby@liu.se

Rodrigo Moreno; $\quad$ rodrigo.moreno@liu.se

Torkel Brismar; $\quad$ torkel.brismar@gmail.com

Corresponding author:

Eva Klintström

Department of Radiology

University Hospital

58185 Linköping

Sweden

Telephone number: $+4610-1038573$

Email address: eva.klintstrom@lio.se

Fax number: +4610-1032709 


\begin{abstract}
Objective. Bone strength depends on both mineral content and bone structure. The aim of this in vitro study was to develop a method for quantitative assessment of trabecular bone structure by applying three-dimensional image processing to data acquired with multi-slice and cone-beam computed tomography using micro-computed tomography as reference.
\end{abstract}

Material and Methods. 15 bone samples from the radius were examined. After segmentation, quantitative measures of bone volume, trabecular thickness, trabecular separation, trabecular number, trabecular nodes and trabecular termini were obtained.

Results. Both clinical machines overestimated bone volume and trabecular thickness and underestimated trabecular nodes and number but cone-beam CT to a lesser extent. Parameters obtained from cone beam CT were strongly correlated to $\mu \mathrm{CT}$, with correlation coefficients between 0.93 and 0.98 for all parameters except trabecular termini.

Conclusions. The high correlation between cone-beam CT and micro-CT suggest the possibility to quantify and monitor changes of trabecular bone microarchitecture in vivo using cone beam CT.

\title{
Keywords
}

trabecular bone structure; cone-beam computed tomography; micro computed tomography; multi-slice computed tomography; bone segmentation 


\section{Introduction}

Bone strength, which is an important determinant of osteoporosis-related fractures, depends on the mineral content as well as the internal structure [1]. To assess the bone mineral content, the method most frequently used in clinical practice is measuring bone mineral density

(BMD) with dual energy X-ray absorptiometry (DXA) [2]. This method estimates the mineral content per projected bone area $\left(\mathrm{g} / \mathrm{cm}^{2}\right)$ from a two-dimensional image, but does not describe the trabecular bone structure. This limits its ability to fully predict the mechanical properties of the bone.

Several studies have shown that mainly the trabecular bone is affected in osteoporosis, and that the bone structure has great importance for the biomechanical competence [3]. Clinical studies show that the risk of vertebral fractures is higher with disconnections in the trabecular bone network $[4,5]$.

Trabecular bone microarchitecture can be described using different parameters [6]. In vitro, bone structure can be described and measured by destructive histomorphometry and by microcomputed tomography $(\mu \mathrm{CT})$. Good agreement between $\mu \mathrm{CT}$ and destructive histomorphometry has been demonstrated [7]. In vivo imaging of the trabecular bone is feasible by using magnetic resonance imaging (MRI) [8-10]. High-resolution peripheral CT (HR-pQCT) is used for visualization of trabecular bone structures in the peripheral skeleton e.g. calcaneus and wrist $[11,12]$. It would be attractive to be able to use also other clinical available CT scanners for osteoporotic research of more central parts of the body.

A pilot study using images acquired through multi-slice CT (MSCT) and the ARG-algorithm to describe skeletal microstructure evaluated, with promising outcome, the results using $\mu \mathrm{CT}$ as reference [13].

A relatively recently developed acquisition technique, cone-beam computed tomography (CBCT), is used in diagnosing dental, maxillofacial and temporal bone structures [14]. CBCT provides images with isotropic voxels in the range of $80-400 \mu \mathrm{m}$. A few articles are published in the field of describing bone microstructure on images acquired by CBCT $[15,16]$. Several studies describe the microstructure of bone imaged by $\mu \mathrm{CT}$ [17-19]. There are also articles analyzing trabecular bone with MSCT, comparing it with $\mu \mathrm{CT}$ [20-22]. It would therefore be interesting to compare measures describing the bone microstructure obtained from MSCT and CBCT with such from $\mu \mathrm{CT}$ in order to quantitatively describe trabecular bone structure with a technique potentially applicable in vivo.

The aim of this work was to develop a method for quantitative assessment of trabecular bone structure by applying three-dimensional (3D) image processing methods to data acquired with MSCT and CBCT in vitro and to correlate it to the reference method $\mu \mathrm{CT}$. 


\section{Material and methods}

Material

The samples in this study consisted of 15 bone biopsies from the radius, the forearm, of

human cadavers donated for medical research. The research was in accordance to the ethical guidelines regulating such donations. The biopsies were approximately cubic with a side of 10 $\mathrm{mm}$. Each cube included a portion of cortical bone on one side to facilitate orientation. The bone samples were placed in a test tube filled with water and the tubes were placed in the center of a paraffin cylinder, with a diameter of approximately $10 \mathrm{~cm}$, representing soft tissue to simulate measurements in vivo. After imaging, a cube, approximately $8 \mathrm{~mm}$ in side, with only trabecular bone was digitally extracted from each dataset for analysis.

\section{Image acquisition and reconstruction}

The specimens were examined in two different 64-slice MSCT machines, one Siemens Definition (Siemens AG, Erlangen, Germany) and one Light Speed VCT (GE Medical Systems, Milwaukee, WI, USA). On the Siemens MSCT, two levels of the slice thickness and of the mAs setting were used. The images from GE MSCT were reconstructed with two different reconstruction filters, "bone" and "bone plus". The CBCT machine used was 3D

Accuitomo FPD 80 (J. Morita Mfg. Corp., Kyoto, Japan). Acquisition parameters are found in Table 1 and sample images in fig 1 a-f.

The $\mu \mathrm{CT}$ data were acquired with a small desktop CT used for analyzing biopsies and other specimens ( $\mu$ CT 40; SCANCO Medical AG, Bassersdorf, Switzerland). The tube voltage was set to $70 \mathrm{kVp}$ and the voxels had an isotropic resolution of $0.02 \mathrm{~mm}$.

\section{Image processing} $\mathrm{CBCT}$ and $\mu \mathrm{CT}$ voxels were isotropic. The CBCT had voxel sizes of $0.125 \mathrm{~mm}$ and $0.08 \mathrm{~mm}$ and the $\mu \mathrm{CT}$ had a voxel size of $0.02 \mathrm{~mm}$. To obtain almost isotropic voxels from the MSCT, the sections were averaged to voxel size $0.188 \times 0.188 \times 0.200 \mathrm{~mm}$ for the GE MSCT and to $0.098 \times 0.098 \times 0.098 \mathrm{~mm}$ for the Siemens MSCT datasets.

Segmentation, an important part of the 3D image processing in this study, aims at delineating bone from other tissues. Voxels representing bone are then assigned the value one and the remaining voxels the value zero, resulting in a binary image. We have used the automated 3D region growing algorithm based on an assessment function (ARG) [23]. Similarly to many other mathematical morphology-based techniques, ARG has been devised for images with isometric voxels. Thus it is necessary to perform an interpolation before ARG is applied, in case the images have non-isometric voxels. In our case such an interpolation was necessary for the MSCT images. The ARG method starts with a very limited homogeneity threshold which results in an under-segmented region. The image processing is then repeated with a higher threshold and the procedure is iterated. A segmentation, that was used to calculate the parameters, was defined as the iteration where the assessment function attained its minimum. Representative images demonstrating raw image, segmented image and 3D image from $\mu \mathrm{CT}$ data are shown in (Fig 1c and Fig 2a-b).

The quantitative parameters of bone structure were calculated using MATLAB. The MATLAB code used for segmenting the images was developed in house. The computer used was a standard PC with Intel Core i5, CPU at $2.60 \mathrm{GHz}, 4 \mathrm{~GB}$ of RAM and 64-bit operating system. Six different parameters were measured and are listed below: 
Bone volume over total volume (BV/TV) is measured by dividing the number of voxels classified as bone trabecula by the total number of voxels in the bone sample. (Fig 3a)

Trabecular thickness (Tb.Th) is measured in mm, the mean trabecular bone diameter (Fig 3b)

Trabecular separation (Tb.Sp), also measured in $\mathrm{mm}$, the mean distance between the boundaries of the segmented trabeculae. (Fig 3c)

Trabecular number (Tb.N) is the number of the trabeculae, measured as the inverse of the mean spacing between the midlines of the trabeculae. (Fig 3c)

Trabecular nodes (Tb.Nd) is the number of trabecular intersections per volume. (Fig 3b) Trabecular termini (Tb.Tm) is the number of free ends of trabeculae per volume. (Fig 3b)

\section{Statistical methods}

Results are presented as mean values with standard deviations. Parameters are related to each other using Pearson correlation with 95\% confidence intervals. 


\section{Results}

With all clinical machines, BV/TV and Tb.Th were consistently overestimated relative to $\mu \mathrm{CT}$. The CBCT machine overestimated Tb.Th three times or more and the GE MSCT overestimated Tb.Th almost five times. (Fig 4 and 6; Table 2).

Both MSCT machines overestimated BV/TV more than four times and the CBCT machine more than three times. Tb.Nd was highly underestimated by all the clinical machines relative to $\mu \mathrm{CT}$. (Fig 5 and 7; Table 2).

The GE MSCT machines underestimated Tb.Nd more than 10 times and showed very small variations in this parameter between the bone samples.

All clinical CT machines showed strong correlation with $\mu \mathrm{CT}$ regarding BV/TV $(r>0.86)$ (Table 3). For the Tb.Th, both the CBCT and the Siemens MSCT showed strong correlation $(r>0.86)$.

When images reconstructed with the two different reconstruction filters from the GE MSCT ("bone" and "bone plus") were compared, the "bone plus" filter had slightly stronger correlations to the $\mu \mathrm{CT}$ measurements for all parameters than those of the "bone" filter (Table 3). The differences between the mean values obtained with the two filters were small (Table 2).

Regarding the Siemens MSCT, the obtained Tb.Sp, Tb.N and Tb.Nd had weak correlations with those of $\mu \mathrm{CT}$ when using $0.6 \mathrm{~mm}$ slice thickness $(r=0.12,0.15$ and 0.02 respectively), but was much stronger when using $0.4 \mathrm{~mm}$ slice thickness $(r=0.52,0.66$ and 0.70 respectively). Tb.Th and BV/TV had almost the same correlation to those of $\mu \mathrm{CT}$ regardless of the slice thickness $(r=0.88-0.92)$ (Table 3).

The bone samples were imaged by CBCT with two different isotropic voxel sizes, $80 \mu \mathrm{m}$ and $125 \mu \mathrm{m}$. For both voxel sizes the observed correlations to $\mu \mathrm{CT}$ were above 0.80 for all parameters except for $\mathrm{Tb}$.Tm where the correlation was 0.73 . When using a voxel size of 80 $\mu \mathrm{m}$ the correlation coefficients ranged from 0.93 to 0.97 for BV/TV, Tb.Th, Tb.N and Tb.Nd (Table 3). 


\section{Discussion}

When describing the micro architecture of the trabecular bone the image resolution turned out to be of great importance. When describing parameters sensitive to differences in the trabecular network such as Tb.Nd and Tb.N, CBCT showed much higher correlations with

$\mu \mathrm{CT}$ than MSCT did. The correlations of CBCT were as high as 0.93 and 0.95 respectively for the $80 \mu \mathrm{m}$ isotropic voxels, while the relatively low resolution of MSCT with $>400 \mu \mathrm{m}$ isotropic voxels resulted in much lower correlations (Table 3). It should be noted that for MSCT, the choice of reconstruction filter ("bone" vs. "bone-plus" on the GE machine) did have an effect on the results. It cannot be excluded that even better results might be attained with a different filter, but with the hardware and software available, these were the filters that were expected to give the best results. On the other hand, when describing parameters less sensitive to image resolution, such as BV/TV all studied machines showed strong correlations to those of $\mu \mathrm{CT}(\mathrm{r}>0.87)$, regardless of resolution or filter. There was also a strong correlation for $\mathrm{Tb}$.Th when using MSCT from Siemens, as well as when using the CBCT machine. However, both BV/TV and Tb.Th describe the mineral content, just like DXA, but fail to describe the complexity of the microarchitecture.

A recent article describing trabecular bone microarchitecture in the maxilla found positive correlations between $\mu \mathrm{CT}$ and CBCT (with resolution $400 \mu \mathrm{m}$ ) regarding BV/TV $(r=0.77$ ), Tb.N $(r=0.52)$ and Tb.Th $(r=0.49)$ [24]. In our study, using CBCT with higher resolution $(80 \mu \mathrm{m})$, the correlations for the same parameters were considerably higher: BV/TV $r=0.97$, Tb.N $r=0.95$ and Tb.Th $r=0.96$. CBCT either overestimated or underestimated the bone structure parameters compared to $\mu \mathrm{CT}$. Such systematic errors can be tolerated if the purpose is to make intra-individual comparisons over time to, e.g. evaluate medical treatment. High correlations with the gold standard can also make it possible to estimate the bone structure in individuals with measurements at only one occasion if one takes into account the known relationship between the measurements from different machines. Our study was an in vitro study and the bone specimens were defatted and surrounded by water. This may affect the results compared to studies on viable bone. Our measurements, imaged by $\mu \mathrm{CT}$, describing Tb.N, Tb.Th as well as Tb.Sp are in good agreement with other studies indicating that the results are credible $[25,26]$.

When imaging facial structures, CBCT machines are usually used with the patient in either sitting or standing position. The long acquisition time, between 10 and 35 seconds, increases the risk for motion artifacts, especially when the patient is standing. There are CBCT devices for patients lying down, but those are less widely used. Currently available CBCT equipment does not permit examination of the torso. The prospect of applying CBCT to e.g. vertebral examinations does therefore not seem realistic. Examination of cervical vertebrae is feasible [27], but the radiation dose to the thyroid would probably be an issue if one were to screen for osteoporosis. In order to decrease radiation dose to the thyroid imaging of the wrist could be an appealing alternative. Such a study, in a CBCT device permitting patients to lie down, has recently been published [28]. There are also studies describing finger fractures using CBCT devices, with high correlation with those of MSCT [29] and articles where the wrist is imaged by arthrography and $\mathrm{CBCT}$ [30]. If the wrist is going to be imaged in our CBCT machine, some kind of fixation device for the wrist needs to be developed in order to minimize the risk for motion artifacts and to ensure high reproducibility.

It has previously been shown that there is a correlation between the width of the mandible cortex and BMD of the lumbar spine [31]. By analyzing changes in mandible bone structures from panoramic dental radiographs it has been possible to identify $40-69 \%$ of women at risk 
for future fractures by observing sparse mandibular trabeculation [32]. This indicates that it might be possible to identify persons at risk for osteoporosis by also investigating the 3D trabecular network of the mandible when performing dental examinations by CBCT.

An already existing method for studying the trabecular bone structure at a resolution equivalent to CBCT is HR-pQCT [11]. In a study by Sode et al [33], HR-pQCT data sets of different voxel sizes were correlated to $\mu \mathrm{CT}$, also of different voxel sizes. The correlation for the structure parameters increased when the voxel size for HR-pQCT was close to the voxel size for the $\mu \mathrm{CT}$. This strengthens the conclusion that resolution plays an important role for the ability of the CBCT to describe trabecular bone structures. A disadvantage of HR-pQCT is that it is less wide-spread than CBCT and that it is only used for peripheral body parts. MSCT, on the other hand, is available in most general hospitals. The radiation dose is, however, considerably higher compared to CBCT [34]. Another drawback of MSCT is its lower resolution which, as shown by our present study, results in much lower correlations with $\mu \mathrm{CT}$ for several of the bone structure parameters. MRI is appealing as it does not use any radiation, but susceptibility artifacts cause magnetic field dependent overestimation of the trabeculae [10] and also the cost per examination is rather high compared to many other imaging methods. In addition, the acquisition time is considerably longer than for CBCT.

Future clinical studies are needed to evaluate effects of patient movement as well as other factors that may complicate in vivo acquisition. It would also be interesting to compare CBCT with HR-pQCT with $\mu \mathrm{CT}$ as the reference. As most CBCT scanners are used for dental examinations, there may be free capacity during out-of-office hours, which potentially can be used for research studies and clinical trials.

In conclusion, the very high correlation between $\mathrm{CBCT}$ and $\mu \mathrm{CT}$, for several bone structure parameters, in particular Tb.Nd and Tb.N, suggest that it might be feasible to use CBCT for monitoring changes in the microarchitecture of trabecular bone in vivo.

\section{Conflict of interest}

No conflict of interest

\section{References}

1. Ulrich D, Van Rietbergen B, Laib A, Ruegsegger P. The ability of three-dimensional structural indices to reflect mechanical aspects of trabecular bone. Bone. 1999; 25(1):5560 .

2. Cullum ID, Ell PJ, Ryder JP. X-ray dual-photon absorptiometry: a new method for the measurement of bone density. The British journal of radiology. 1989; 62(739):587-592.

3. Kleerekoper M, Villanueva AR, Stanciu J, Rao DS, Parfitt AM. The Role of 3Dimensional Trabecular Microstructure in the Pathogenesis of Vertebral Compression Fractures. Calcified tissue international. 1985; 37(6):594-597.

4. Aaron JE, Shore PA, Shore RC, Beneton M, Kanis JA. Trabecular architecture in women and men of similar bone mass with and without vertebral fracture: II. Three-dimensional histology. Bone. 2000; 27(2):277-282.

5. Legrand E, Chappard D, Pascaretti C, Duquenne M, Krebs S, Rohmer V, et al. Trabecular bone microarchitecture, bone mineral density, and vertebral fractures in male osteoporosis. J Bone Miner Res. 2000; 15(1):13-19. 
6. Parfitt AM, Drezner MK, Glorieux FH, Kanis JA, Malluche H, Meunier PJ, et al. Bone Histomorphometry - Standardization of Nomenclature, Symbols, and Units. J Bone Miner Res. 1987; 2(6):595-610.

7. Thomsen JS, Laib A, Koller B, Prohaska S, Mosekilde L, Gowin W. Stereological measures of trabecular bone structure: comparison of 3D micro computed tomography with 2D histological sections in human proximal tibial bone biopsies. J Microsc-Oxf. 2005; 218:171-179.

8. Boutry N, Cortet B, Dubois P, Marchandise X, Cotten A. Trabecular bone structure of the calcaneus: preliminary in vivo MR imaging assessment in men with osteoporosis. Radiology. 2003; 227(3):708-717.

9. Jara H, Wehrli FW, Chung H, Ford JC. High-resolution variable flip angle 3D MR imaging of trabecular microstructure in vivo. Magnetic resonance in medicine : official journal of the Society of Magnetic Resonance in Medicine / Society of Magnetic Resonance in Medicine. 1993; 29(4):528-539.

10. Phan CM, Matsuura M, Bauer JS, Dunn TC, Newitt D, Lochmueller EM, et al. Trabecular bone structure of the calcaneus: comparison of MR imaging at 3.0 and $1.5 \mathrm{~T}$ with micro-CT as the standard of reference. Radiology. 2006; 239(2):488-496.

11. Boutroy S, Bouxsein ML, Munoz F, Delmas PD. In vivo assessment of trabecular bone microarchitecture by high-resolution peripheral quantitative computed tomography. The Journal of clinical endocrinology and metabolism. 2005; 90(12):6508-6515.

12. Burrows M, Liu D, Perdios A, Moore S, Mulpuri K, McKay H. Assessing bone microstructure at the distal radius in children and adolescents using HR-pQCT: a methodological pilot study. Journal of clinical densitometry : the official journal of the International Society for Clinical Densitometry. 2010; 13(4):451-455.

13. Petersson J, Brismar T, Smedby O. Analysis of skeletal microstructure with clinical multislice CT. In: Larsen R, Nielsen M, Sporring J, eds. Medical Image Computing and Computer-Assisted Intervention - Miccai 2006, Pt 2. Berlin: Springer-Verlag Berlin; 2006:880-887.

14. Arai Y, Tammisalo E, Iwai K, Hashimoto K, Shinoda K. Development of a compact computed tomographic apparatus for dental use. Dento maxillo facial radiology. 1999; 28(4):245-248.

15. Hohlweg-Majert B, Metzger MC, Kummer T, Schulze D. Morphometric analysis - Cone beam computed tomography to predict bone quality and quantity. Journal of CranioMaxillofacial Surgery. 2011; 39(5):330-334.

16. Hua Y, Nackaerts O, Duyck J, Maes F, Jacobs R. Bone quality assessment based on cone beam computed tomography imaging. Clinical oral implants research. 2009; 20(8):767771.

17. Nageie E, Kuhn V, Vogt H, Link TM, Muller R, Lochmuller EM, et al. Technical considerations for microstructural analysis of human trabecular bone from specimens excised from various skeletal sites. Calcified tissue international. 2004; 75(1):15-22.

18. Bauer JS, Link TM. Advances in osteoporosis imaging. European journal of radiology. 2009; 71(3):440-449.

19. Liu XS, Sajda P, Saha PK, Wehrli FW, Bevill G, Keaveny TM, et al. Complete volumetric decomposition of individual trabecular plates and rods and its morphological correlations with anisotropic elastic moduli in human trabecular bone. J Bone Miner Res. 2008; 23(2):223-235.

20. Bauer JS, Link TM, Burghardt A, Henning TD, Mueller D, Majumdar S, et al. Analysis of trabecular bone structure with multidetector spiral computed tomography in a simulated soft-tissue environment. Calcified tissue international. 2007; 80(6):366-373. 
21. Diederichs G, Link TM, Kentenich M, Schwieger K, Huber MB, Burghardt AJ, et al. Assessment of trabecular bone structure of the calcaneus using multi-detector CT: Correlation with microCT and biomechanical testing. Bone. 2009; 44(5):976-983.

22. Burghardt AJ, Link TM, Majumdar S. High-resolution Computed Tomography for Clinical Imaging of Bone Microarchitecture. Clinical orthopaedics and related research. 2011; 469(8):2179-2193.

23. Revol-Muller C, Peyrin F, Carrillon Y, Odet C. Automated 3D region growing algorithm based on an assessment function. Pattern Recognition Letters. 2002; 23(1-3):137-150.

24. Monje A, Monje F, Gonzalez-Garcia R, Galindo-Moreno P, Rodriguez-Salvanes F, Wang HL. Comparison between microcomputed tomography and cone-beam computed tomography radiologic bone to assess atrophic posterior maxilla density and microarchitecture. Clinical oral implants research. 2013.

25. Tjong W, Kazakia GJ, Burghardt AJ, Majumdar S. The effect of voxel size on highresolution peripheral computed tomography measurements of trabecular and cortical bone microstructure. Medical physics. 2012; 39(4):1893-1903.

26. Kazakia GJ, Burghardt AJ, Link TM, Majumdar S. Variations in morphological and biomechanical indices at the distal radius in subjects with identical BMD. Journal of biomechanics. 2011; 44(2):257-266.

27. Joshi V, Yamaguchi T, Matsuda Y, Kaneko N, Maki K, Okano T. Skeletal maturity assessment with the use of cone-beam computerized tomography. Oral surgery, oral medicine, oral pathology and oral radiology. 2012; 113(6):841-849.

28. De Cock J, Mermuys K, Goubau J, Van Petegem S, Houthoofd B, Casselman JW. Conebeam computed tomography: a new low dose, high resolution imaging technique of the wrist, presentation of three cases with technique. Skeletal radiology. 2012; 41(1):93-96.

29. Faccioli N, Foti G, Barillari M, Atzei A, Mucelli RP. Finger fractures imaging: accuracy of cone-beam computed tomography and multislice computed tomography. Skeletal radiology. 2010; 39(11):1087-1095.

30. Koskinen SK, Haapamaki VV, Salo J, Lindfors NC, Kortesniemi M, Seppala L, et al. CT arthrography of the wrist using a novel, mobile, dedicated extremity cone-beam CT (CBCT). Skeletal radiology. 2013; 42(5):649-657.

31. Vlasiadis KZ, Damilakis J, Velegrakis GA, Skouteris CA, Fragouli I, Goumenou A, et al. Relationship between BMD, dental panoramic radiographic findings and biochemical markers of bone turnover in diagnosis of osteoporosis. Maturitas. 2008; 59(3):226-233.

32. Jonasson G, Sundh V, Hakeberg M, Hassani-Nejad A, Lissner L, Ahlqwist M. Mandibular bone changes in 24 years and skeletal fracture prediction. Clinical oral investigations. 2013; 17(2):565-572.

33. Sode M, Burghardt AJ, Nissenson RA, Majumdar S. Resolution dependence of the nonmetric trabecular structure indices. Bone. 2008; 42(4):728-736.

34. Helmrot E, Thilander-Klang A. Methods for monitoring patient dose in dental radiology. Radiation protection dosimetry. 2010; 139(1-3):303-305. 


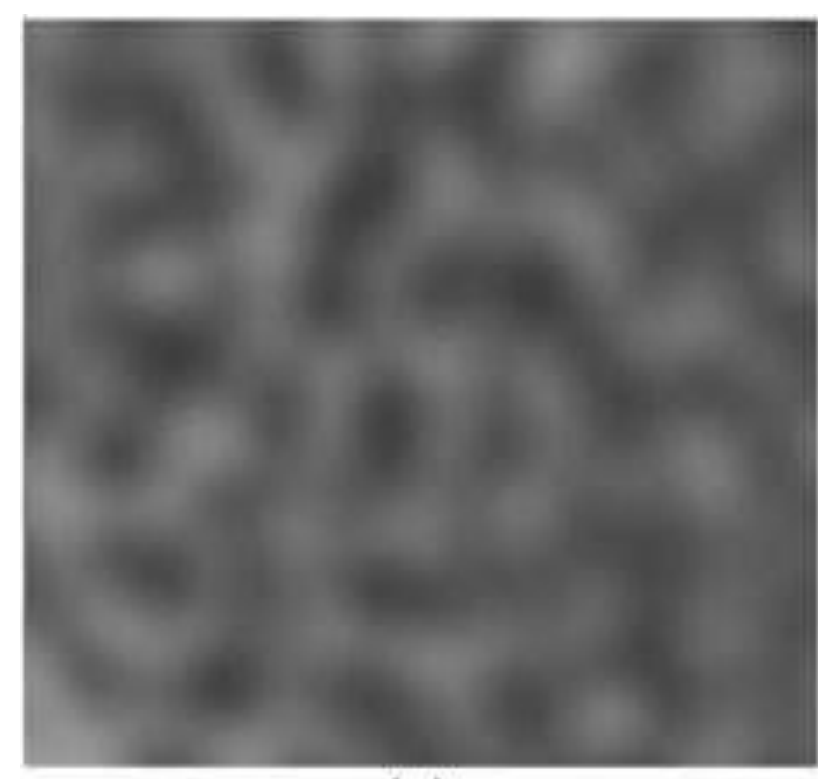

(a)

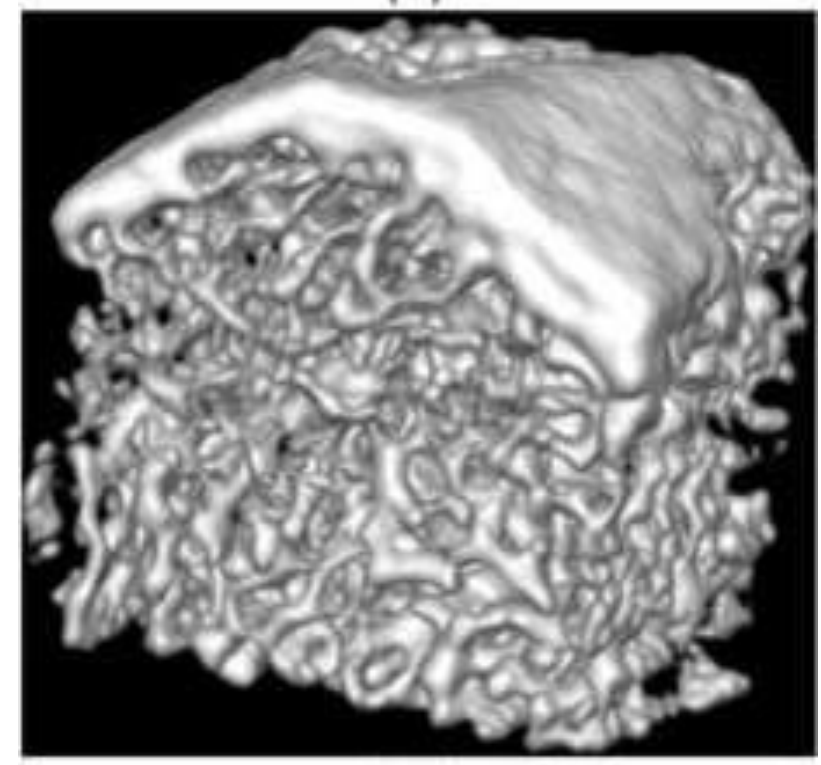

(d)

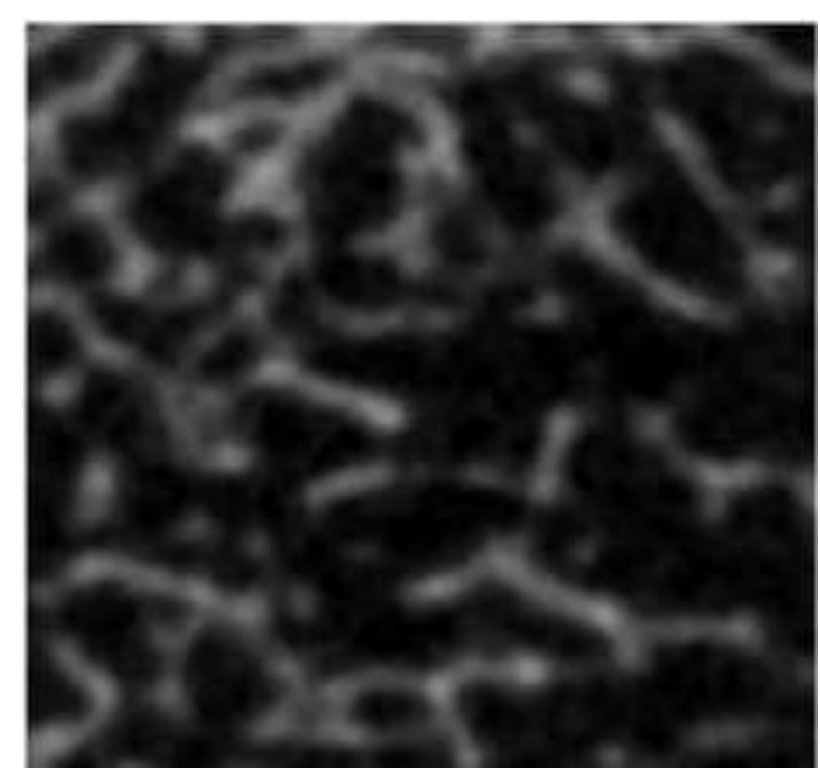

(b)

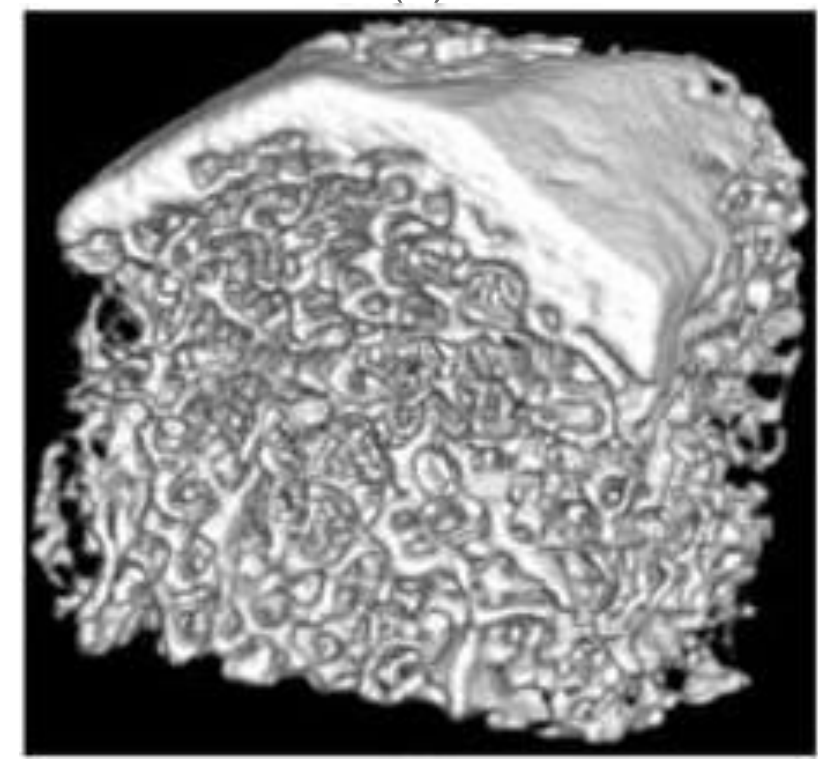

(e)

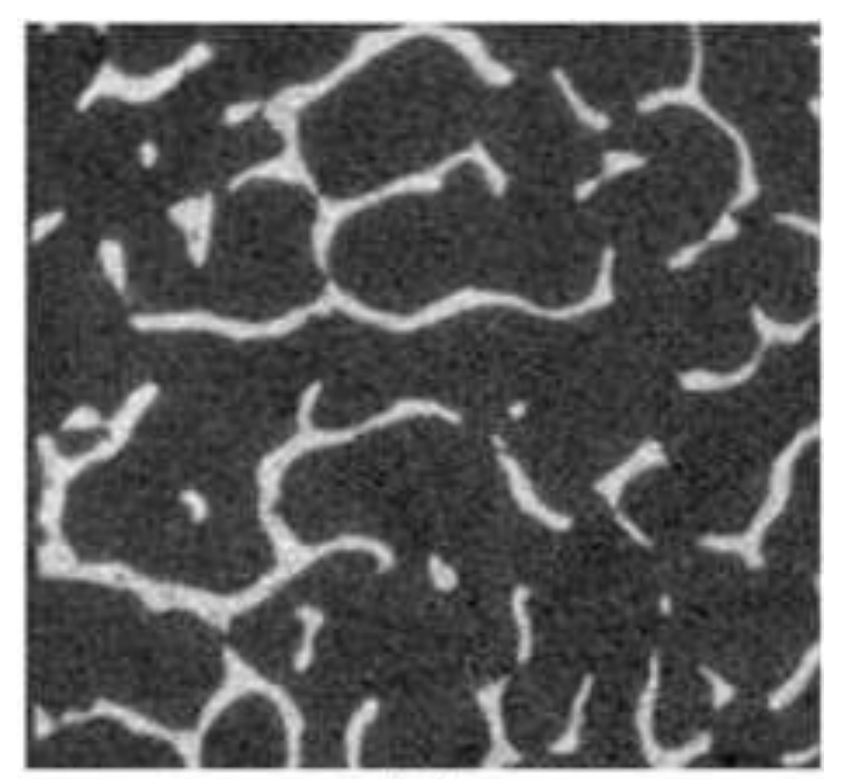

(c)

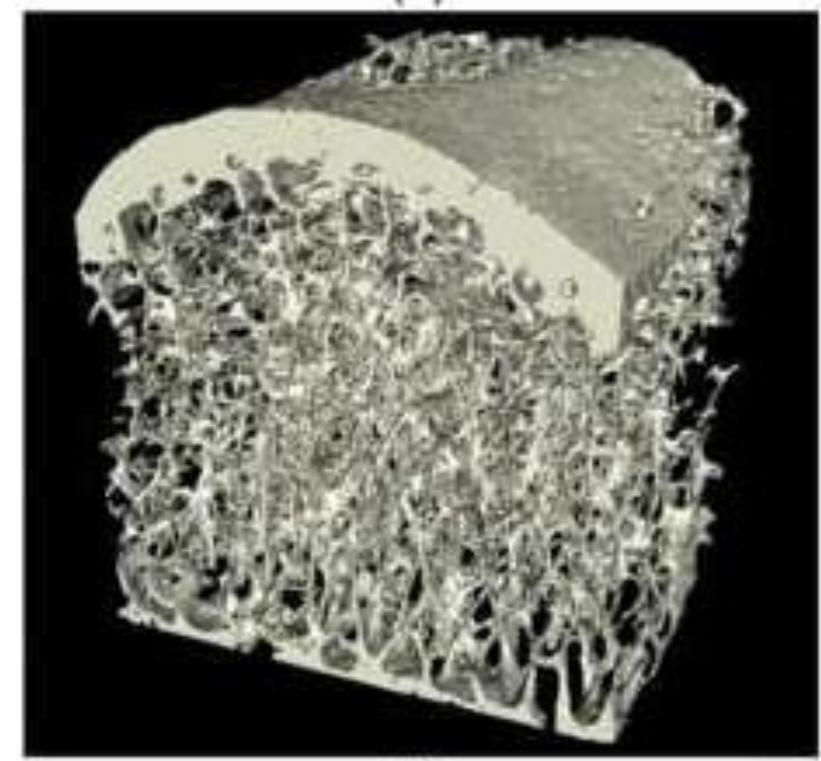

(f) 
Figure 1a

Click here to dOVYmad high resolution mage

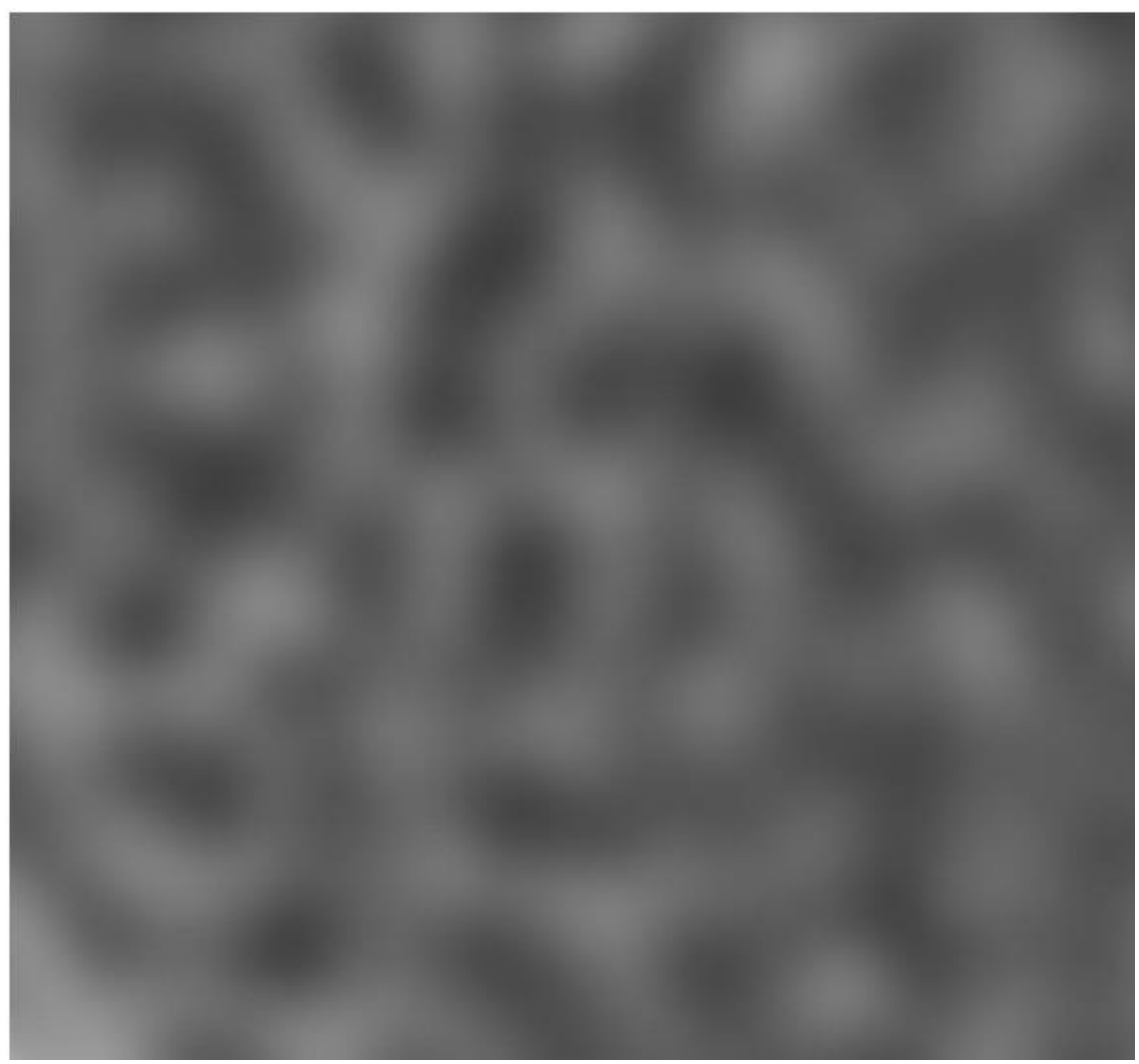

.

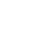


Figure $1 \mathrm{~b}$
Click here to dOVYmad high resolutionimage
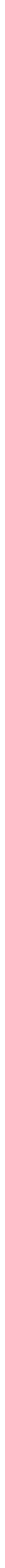
Figure 1c
Click here to dOVY'bad high resolutionmage

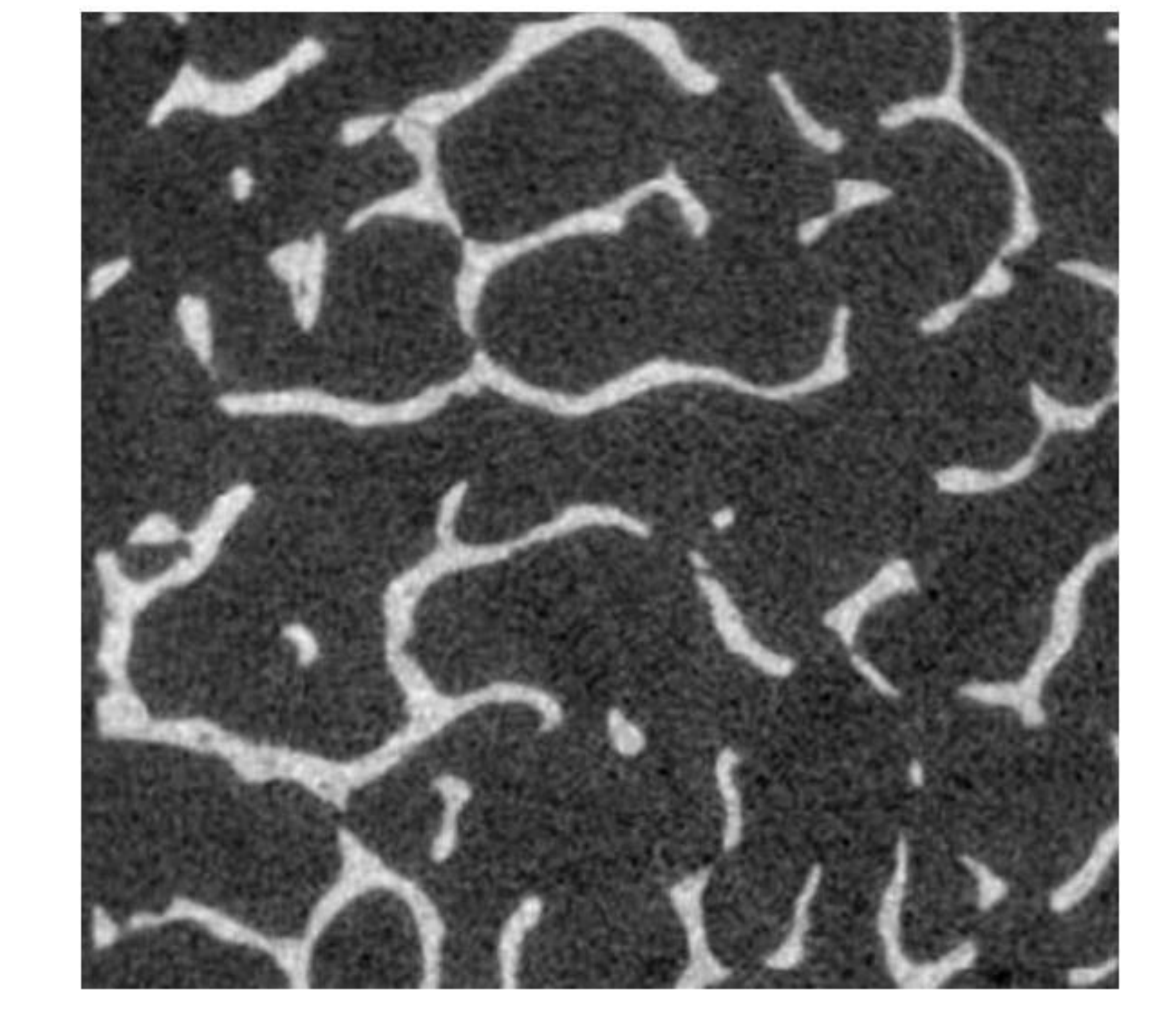

Clck here to dO
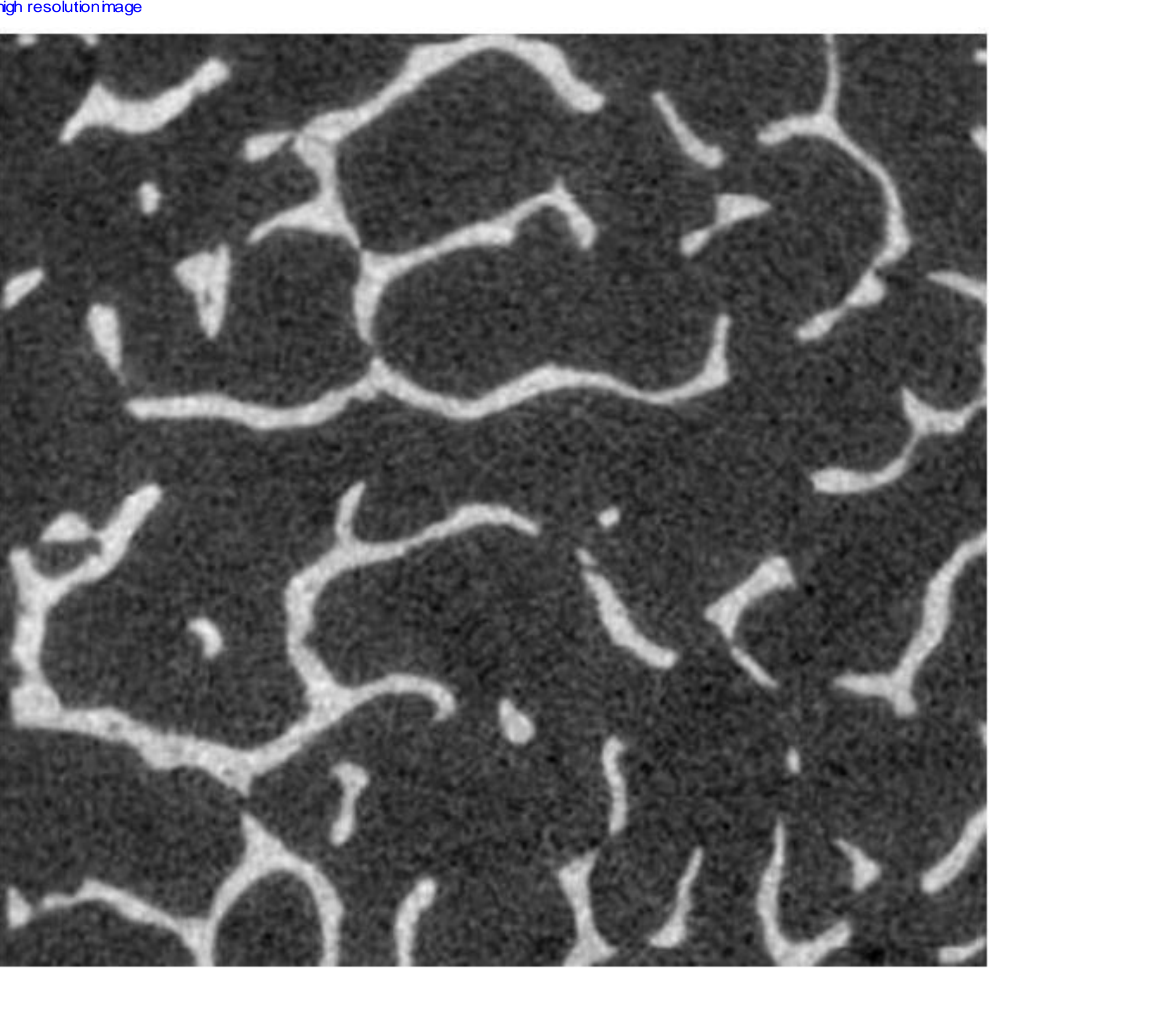

. 


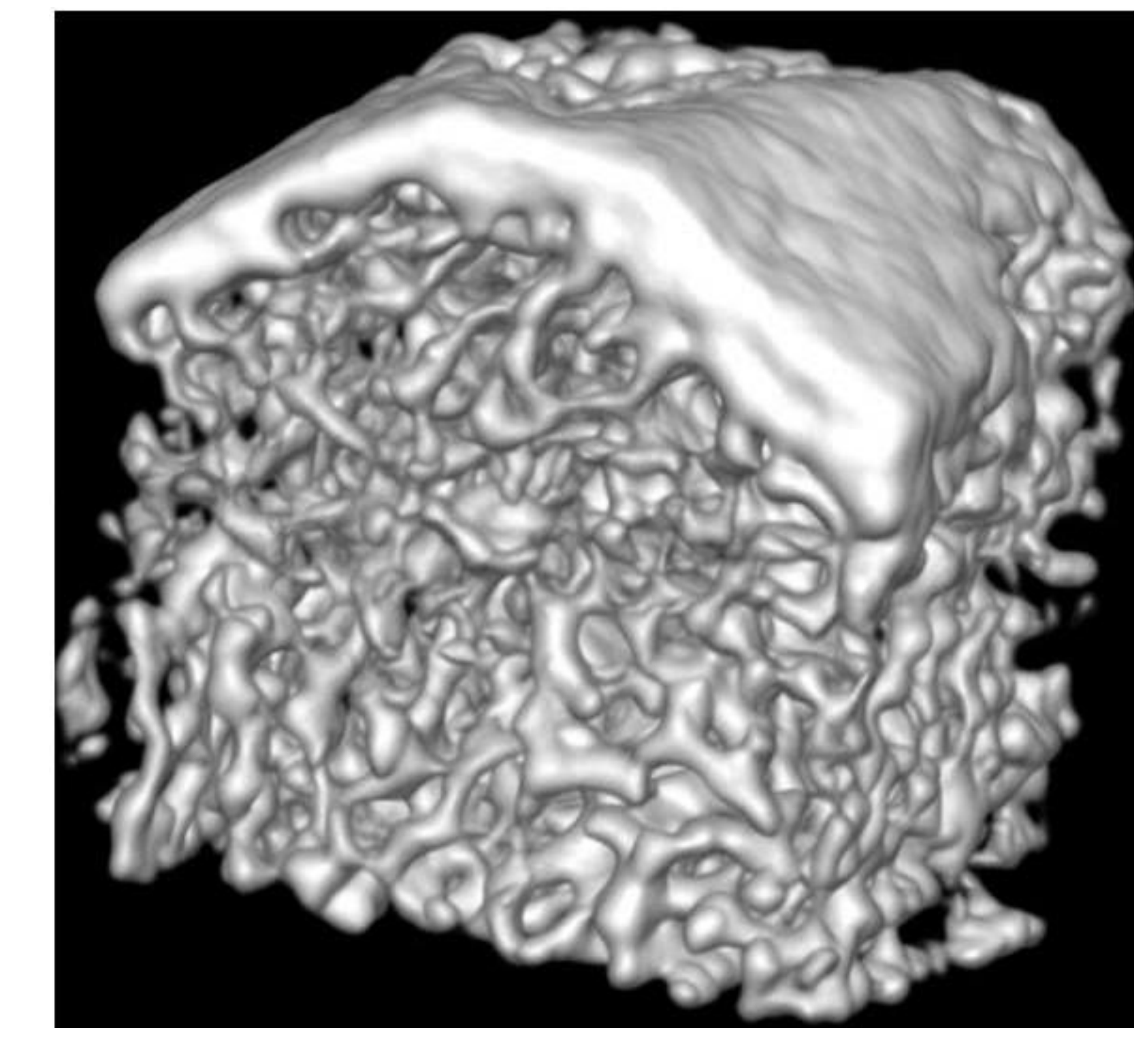

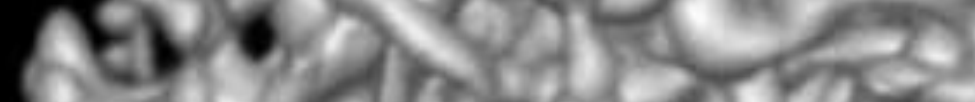

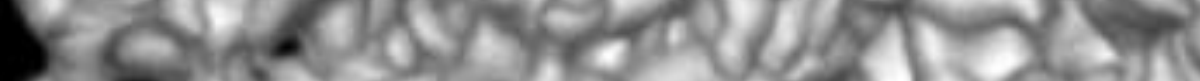

a.m.

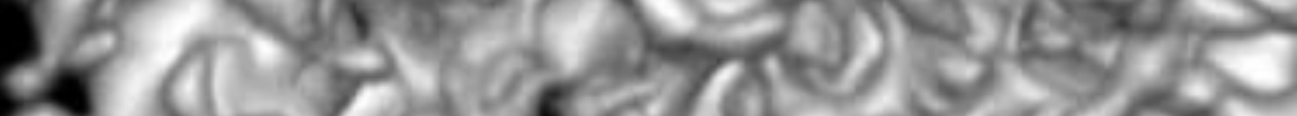

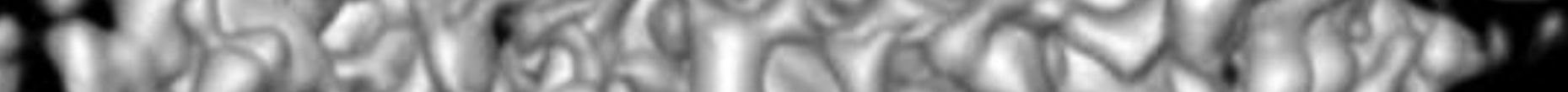

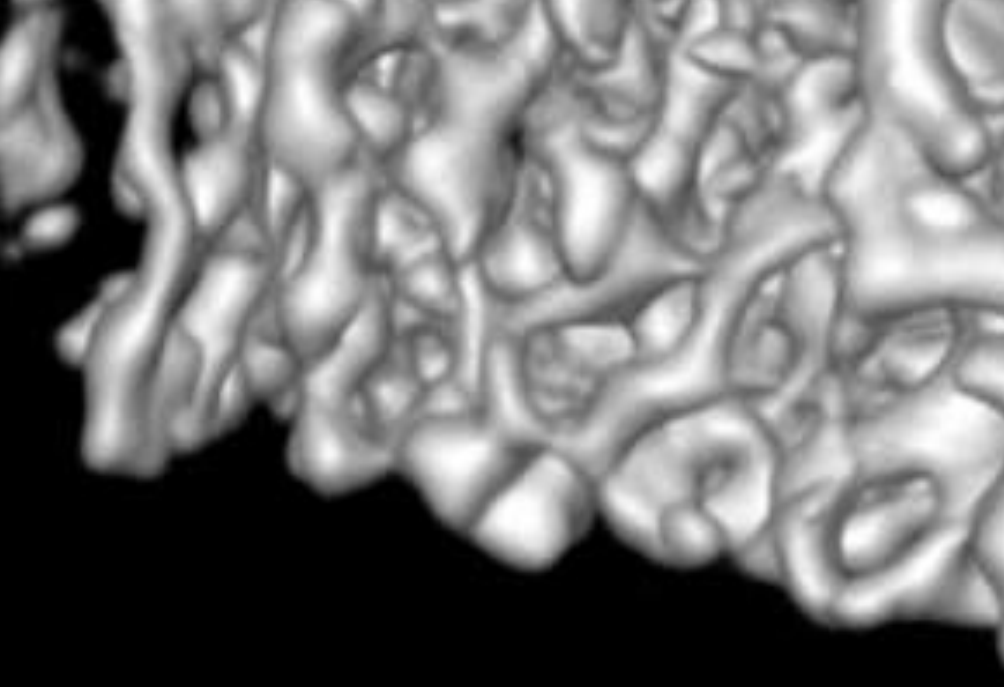

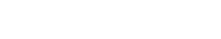

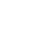

to $d O V Y$




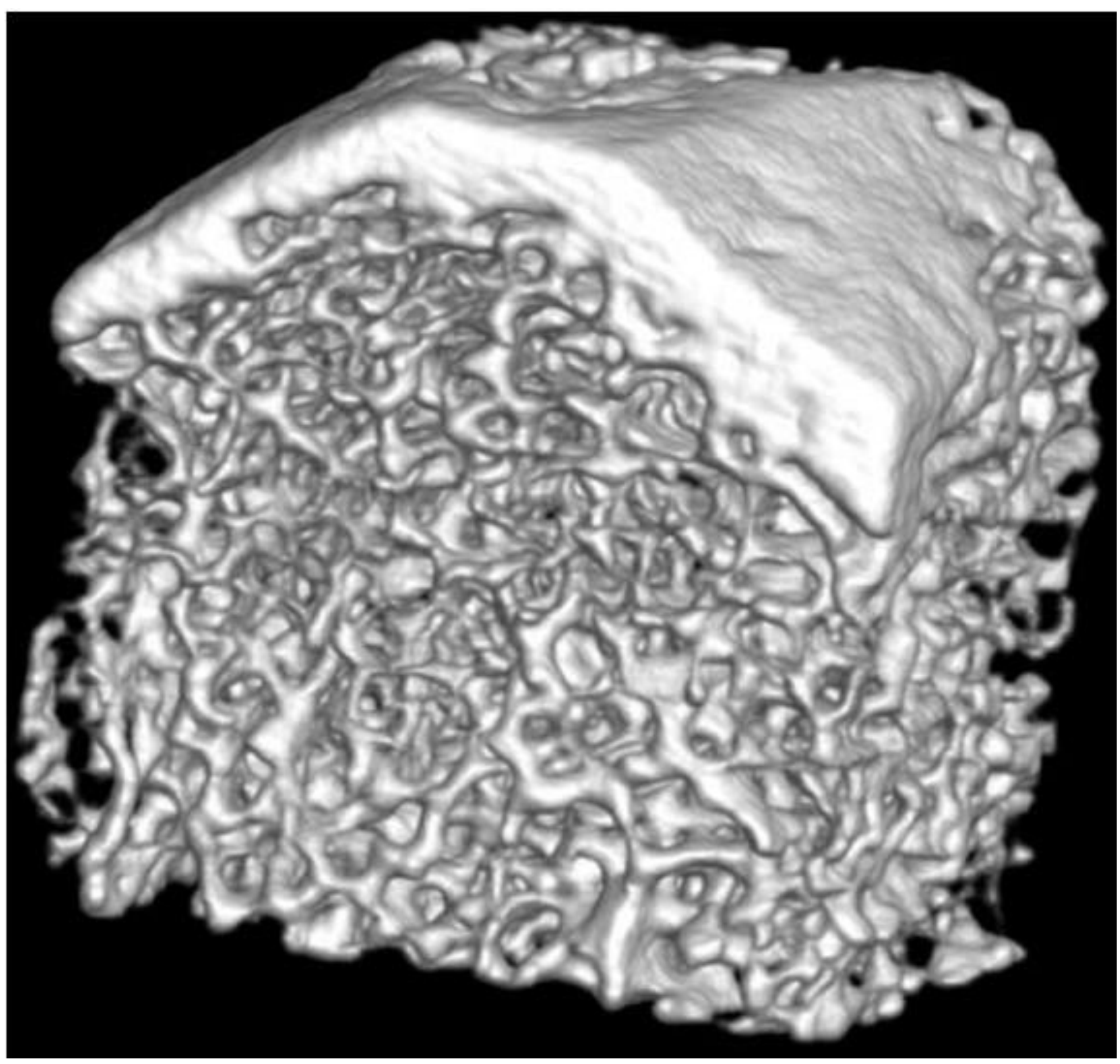

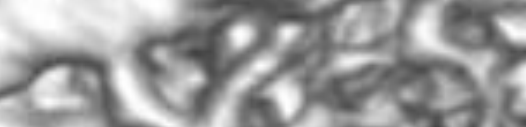

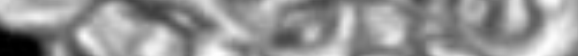

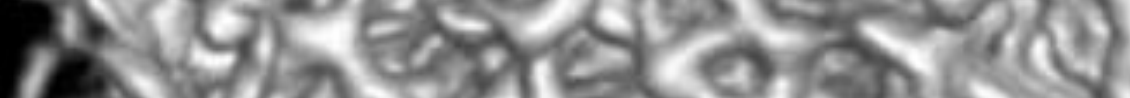

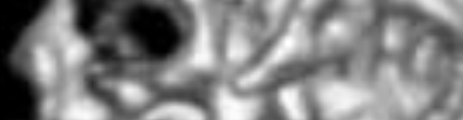

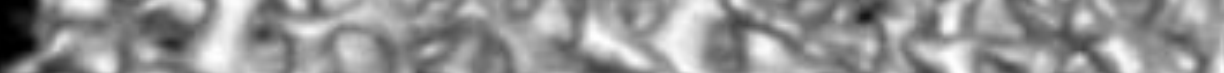

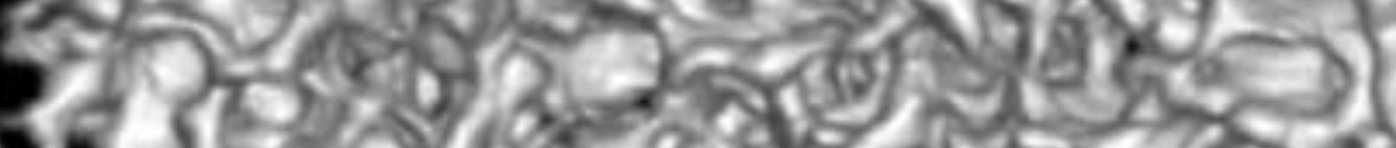

(3)

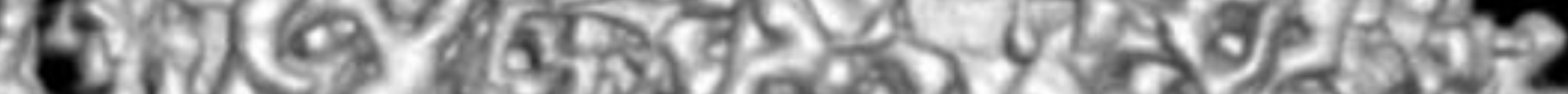

H.

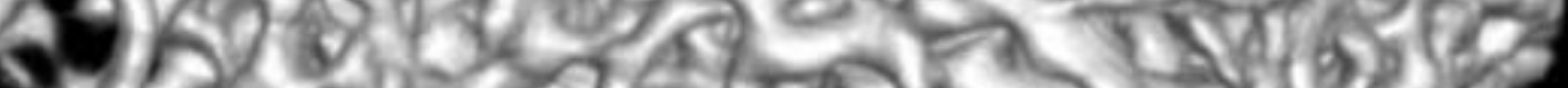
e.

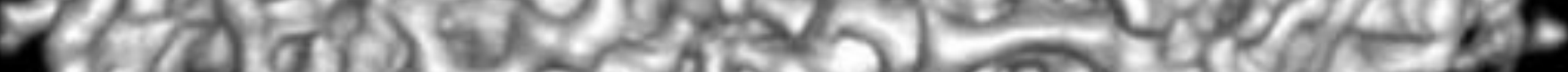

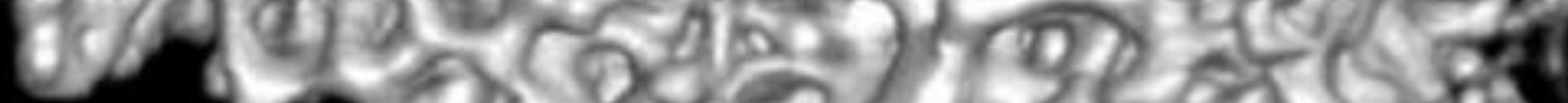

$$
\text { Qif }
$$



Table 1. Imaging parameters

\begin{tabular}{|c|c|c|c|c|c|c|}
\hline & $\begin{array}{c}\text { MSCT } \\
\text { GE Light speed }\end{array}$ & $\begin{array}{c}\text { MSCT } \\
\text { GE Light speed }\end{array}$ & $\begin{array}{c}\text { MSCT } \\
\text { Siemens Definition }\end{array}$ & $\begin{array}{c}\text { MSCT } \\
\text { Siemens Definition }\end{array}$ & $\begin{array}{c}\text { CBCT } \\
\text { Accuitomo FPD } 80\end{array}$ & $\begin{array}{c}\text { CBCT } \\
\text { Accuitomo FPD } 80\end{array}$ \\
\hline Imaging voxel size $[\mu \mathrm{m}]$ & $188 \times 188 \times 625$ & $188 \times 188 \times 625$ & $98 \times 98 \times 600$ & $98 \times 98 \times 400$ & $125 \times 125 \times 125$ & $80 \times 80 \times 80$ \\
\hline Reconstruction voxel size $[\mu \mathrm{m}]$ & $188 \times 188 \times 200$ & $188 \times 188 \times 200$ & $98 \times 98 \times 98$ & $98 \times 98 \times 98$ & $125 \times 125 \times 125$ & $80 \times 80 \times 80$ \\
\hline Tube voltage $[\mathrm{kV}]$ & 120 & 120 & 120 & 120 & 85 & 85 \\
\hline Effective [mAs] & 130 & 130 & 130 & 400 & - & - \\
\hline$[\mathrm{mA}]$ & - & - & - & - & 8 & 8 \\
\hline Field of view [mm] & 96 & 96 & 50 & 50 & 60 & 40 \\
\hline Matrix & $512 \times 512$ & $512 \times 512$ & $512 \times 512$ & $512 \times 512$ & $480 \times 480$ & $500 \times 500$ \\
\hline Reconstruction filter & Bone & Bone plus & U70u sharp & U70u sharp & G001 (dental) & G001 (dental) \\
\hline
\end{tabular}

MSCT $=$ Multi Slice Computed Tomography; $\mathrm{CBCT}=$ Cone Beam Computed Tomography 
Table 2. Measurements of trabecular bone structure parameters. Mean values and standard deviations

\begin{tabular}{|c|c|c|c|c|c|c|c|}
\hline & $\begin{array}{c}\text { MSCT } \\
\text { GE Light speed } \\
625 \mu \mathrm{m} \text { bone }\end{array}$ & $\begin{array}{c}\text { MSCT } \\
\text { GE Light speed } \\
625 \mu \mathrm{m} \text { boneplus }\end{array}$ & $\begin{array}{c}\text { MSCT } \\
\text { Siemens Definition } \\
600 \mu \mathrm{m} \\
\end{array}$ & $\begin{array}{c}\text { MSCT } \\
\text { Siemens Definition } \\
400 \mu \mathrm{m} \\
\end{array}$ & $\begin{array}{c}\text { CBCT } \\
\text { Accuitomo FPD } \\
125 \mu \mathrm{m} \\
\end{array}$ & $\begin{array}{c}\text { CBCT } \\
\text { Accuitomo FPD } \\
80 \mu \mathrm{m} \\
\end{array}$ & $\begin{array}{c}\mu \mathrm{CT} \\
\text { SCANCO } \\
20 \mu \mathrm{m} \\
\end{array}$ \\
\hline Tb.Sp [mm] & $0.80 \pm 0.07$ & $0.80 \pm 0.05$ & $0.55 \pm 0.03$ & $0.60 \pm 0.04$ & $0.67 \pm 0.09$ & $0.57 \pm 0.07$ & $0.65 \pm 0.12$ \\
\hline Tb.Th [mm] & $0.65 \pm 0.03$ & $0.63 \pm 0.02$ & $0.47 \pm 0.04$ & $0.50 \pm 0.04$ & $0.43 \pm 0.02$ & $0.39 \pm 0.03$ & $0.13 \pm 0.02$ \\
\hline Tb.N $\left[\mathrm{mm}^{-3}\right]$ & $0.64 \pm 0.05$ & $0.68 \pm 0.04$ & $0.95 \pm 0.05$ & $0.88 \pm 0.05$ & $0.85 \pm 0.09$ & $0.95 \pm 0.11$ & $1.17 \pm 0.16$ \\
\hline $\mathrm{BV} / \mathrm{TV}$ & $0.40 \pm 0.07$ & $0.42 \pm 0.06$ & $0.46 \pm 0.04$ & $0.44 \pm 0.67$ & $0.30 \pm 0.08$ & $0.31 \pm 0.08$ & $0.10 \pm 0.03$ \\
\hline Tb.Nd $\left[\mathrm{mm}^{-3}\right]$ & $0.26 \pm 0.05$ & $0.30 \pm 0.05$ & $0.46 \pm 0.04$ & $1.1 \pm 0.14$ & $0.74 \pm 0.2$ & $1.53 \pm 0.43$ & $5.11 \pm 1.67$ \\
\hline Tb.Tm $\left[\mathrm{mm}^{-3}\right]$ & $0.14 \pm 0.02$ & $0.15 \pm 0.03$ & $0.88 \pm 0.08$ & $0.79 \pm 0.1$ & $0.31 \pm 0.07$ & $1.01 \pm 0.27$ & $0.84 \pm 0.08$ \\
\hline
\end{tabular}

MSCT = Multi Slice Computed Tomography; $\mathrm{CBCT}=$ Cone Beam Computed Tomography; $\mu \mathrm{CT}=$ micro Computed Tomography

Bold figures denote values closest to the reference method $(\mu \mathrm{CT})$ 
Table 3. Correlations with $\mu \mathrm{CT}$. Pearson correlation coefficients (r) with $95 \%$ confidence limits.

\begin{tabular}{|c|c|c|c|c|c|c|}
\hline & $\begin{array}{c}\text { MSCT } \\
\text { GE Light speed } \\
\text { Bone }\end{array}$ & $\begin{array}{c}\text { MSCT } \\
\text { GE Light speed } \\
\text { Bone plus }\end{array}$ & $\begin{array}{c}\text { MSCT } \\
\text { Siemens Definition } \\
600 \mu \mathrm{m}\end{array}$ & $\begin{array}{c}\text { MSCT } \\
\text { Siemens Definition } \\
400 \mu \mathrm{m}\end{array}$ & $\begin{array}{c}\text { CBCT } \\
\text { Accuitomo FPD } 80 \\
125 \mu \mathrm{m}\end{array}$ & $\begin{array}{c}\text { CBCT } \\
\text { Accuitomo FPD } 80 \\
80 \mu \mathrm{m}\end{array}$ \\
\hline Tb.Sp & $\begin{array}{c}0.80 \\
(0.49 ; 0.93)\end{array}$ & $\begin{array}{c}\mathbf{0 . 9 1} \\
(0.73 ; 0.97)\end{array}$ & $\begin{array}{c}0.12 \\
(-0.42 ; 0.60)\end{array}$ & $\begin{array}{c}0.52 \\
(0.01 ; 0.81)\end{array}$ & $\begin{array}{c}0.82 \\
(0.52 ; 0.94)\end{array}$ & $\begin{array}{c}0.85 \\
(0.59 ; 0.95)\end{array}$ \\
\hline Tb.Th & $\begin{array}{c}0.47 \\
(-0.06 ; 0.79)\end{array}$ & $\begin{array}{c}0.58 \\
(0.10 ; 0.84) \\
\end{array}$ & $\begin{array}{c}0.89 \\
(0.70 ; 0.96) \\
\end{array}$ & $\begin{array}{c}0.88 \\
(0.66 ; 0.96) \\
\end{array}$ & $\begin{array}{c}0.87 \\
(0.64 ; 0.96) \\
\end{array}$ & $\begin{array}{c}\mathbf{0 . 9 6} \\
(0.88 ; 0.99) \\
\end{array}$ \\
\hline Tb.N & $\begin{array}{c}0.76 \\
(0.41 ; 0.92)\end{array}$ & $\begin{array}{c}0.79 \\
(0.47 ; 0.93)\end{array}$ & $\begin{array}{c}0.15 \\
(-0.39 ; 0.62)\end{array}$ & $\begin{array}{c}0.66 \\
(0.22 ; 0.87)\end{array}$ & $\begin{array}{c}0.90 \\
(0.71 ; 0.97)\end{array}$ & $\begin{array}{c}\mathbf{0 . 9 5} \\
(0.86 ; 0.98)\end{array}$ \\
\hline $\mathrm{BV} / \mathrm{TV}$ & $\begin{array}{c}0.89 \\
(0.71 ; 0.96)\end{array}$ & $\begin{array}{c}\mathbf{0 . 9 4} \\
(0.81 ; 0.98)\end{array}$ & $\begin{array}{c}\mathbf{0 . 9 2} \\
(0.76 ; 0.97)\end{array}$ & $\begin{array}{c}0.87 \\
(0.65 ; 0.96)\end{array}$ & $\begin{array}{c}\mathbf{0 . 9 6} \\
(0.88 ; 0.99)\end{array}$ & $\begin{array}{c}\mathbf{0 . 9 7} \\
(0.92 ; 0.99)\end{array}$ \\
\hline Tb.Nd & $\begin{array}{c}0.74 \\
(0.36 ; 0.91)\end{array}$ & $\begin{array}{c}0.78 \\
(0.44 ; 0.92)\end{array}$ & $\begin{array}{c}0.02 \\
(-0.53 ; 0.50)\end{array}$ & $\begin{array}{c}0.70 \\
(0.29 ; 0.89)\end{array}$ & $\begin{array}{c}0.86 \\
(0.62 ; 0.95)\end{array}$ & $\begin{array}{c}\mathbf{0 . 9 3} \\
(0.80 ; 0.98)\end{array}$ \\
\hline Tb.Tm & $\begin{array}{c}0.06 \\
(-0.47 ; 0.55)\end{array}$ & $\begin{array}{c}0.06 \\
(-0.46 ; 0.55)\end{array}$ & $\begin{array}{c}0.63 \\
(0.18 ; 0.86)\end{array}$ & $\begin{array}{c}0.53 \\
(0.03 ; 0.82)\end{array}$ & $\begin{array}{c}0.73 \\
(0.34 ; 0.90)\end{array}$ & $\begin{array}{c}0.73 \\
(0.34 ; 0.90)\end{array}$ \\
\hline
\end{tabular}

MSCT = Multi Slice Computed Tomography; CBCT = Cone Beam Computed Tomography

$\mathrm{Tb} . \mathrm{Sp}=$ Trabecular separation; Tb.Th = Trabecular thickness; Tb.N = Trabecular number; BV/TV = Bone volume; Tb.Nd = Trabecular number; Tb.Tm = Trabecular termini

Bold figures denote correlations above 0.90 .

Italic figures denote correlations not significantly different from 0 . 


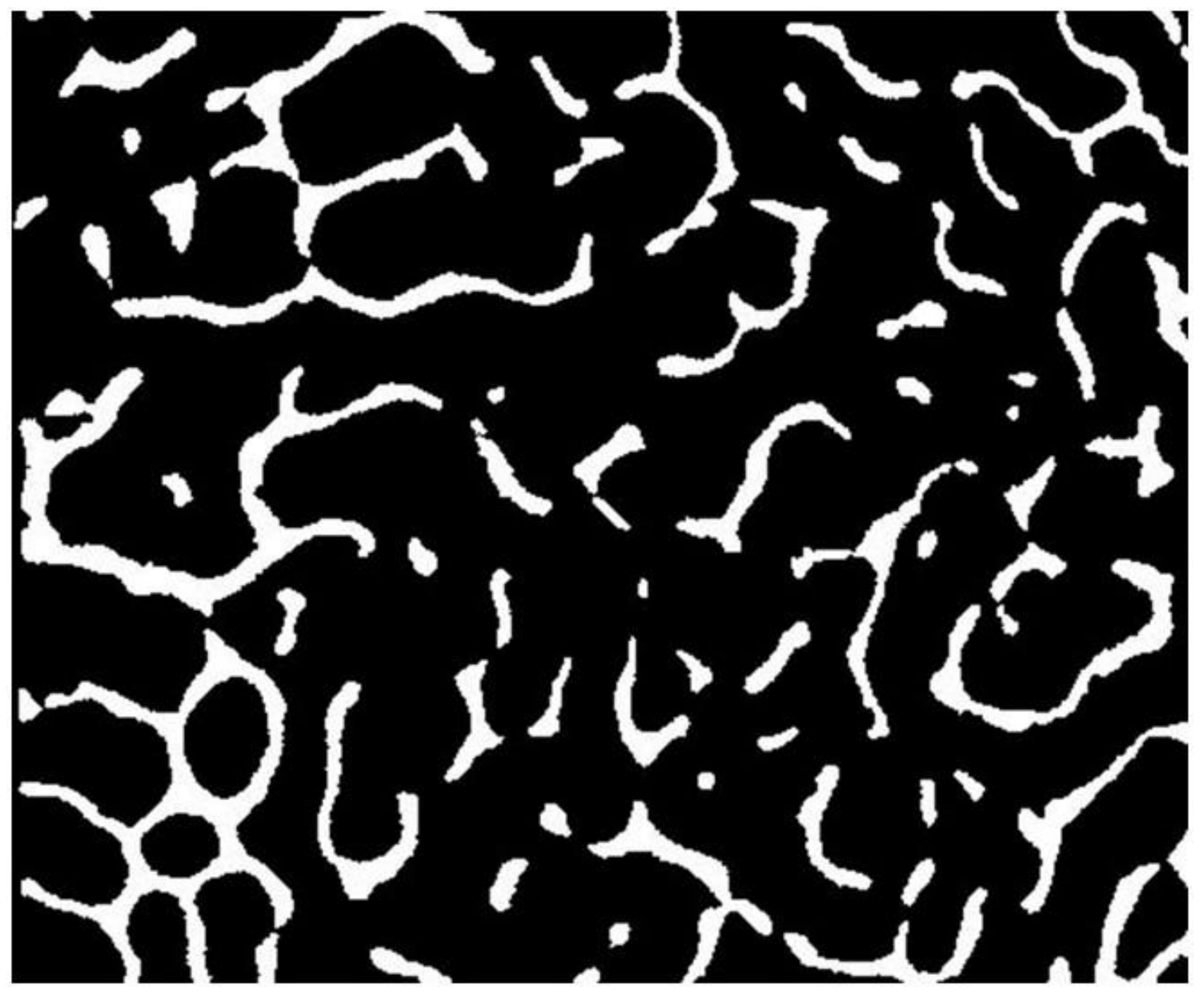




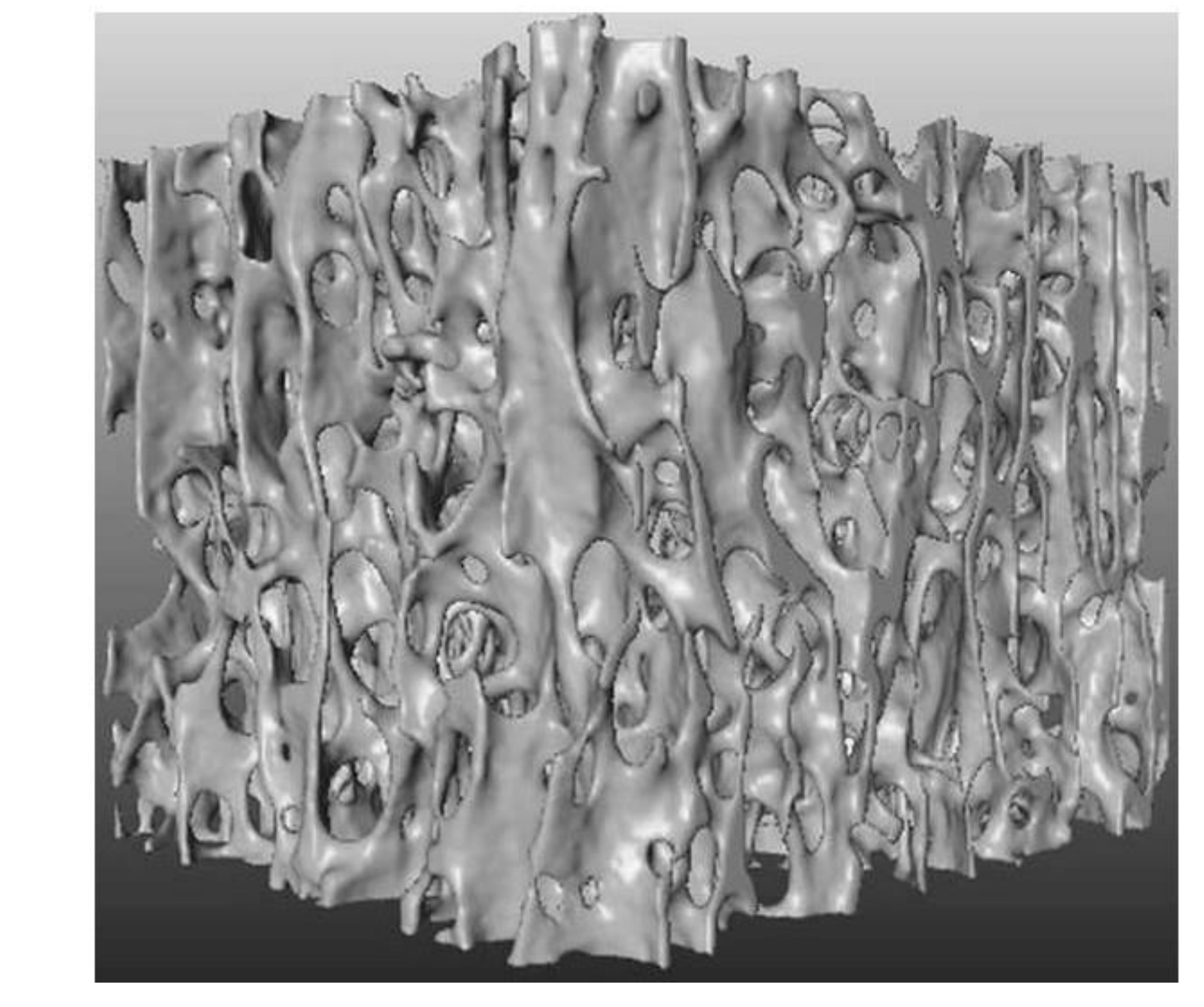

odOVYibad high resolution mage 
BV/TV

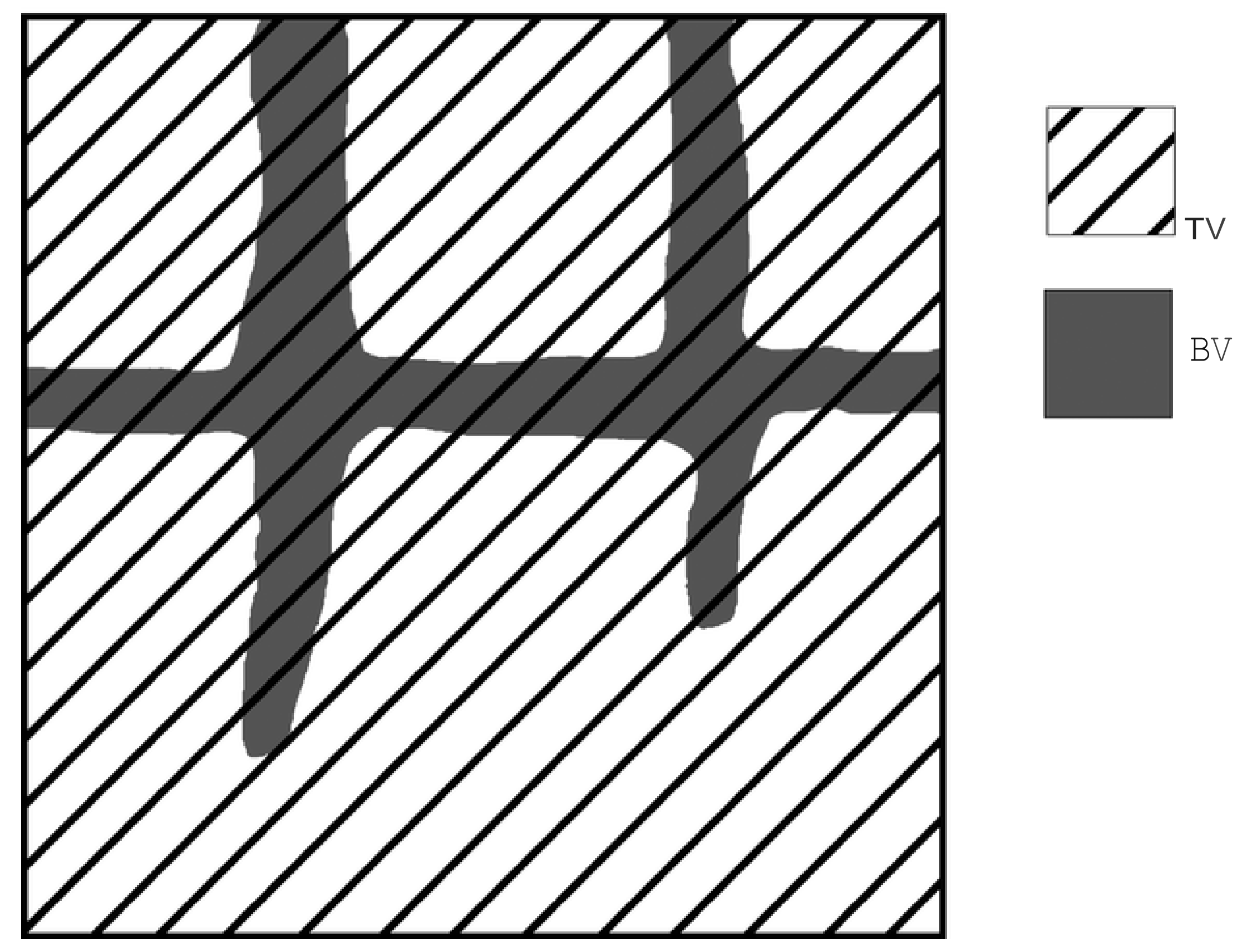




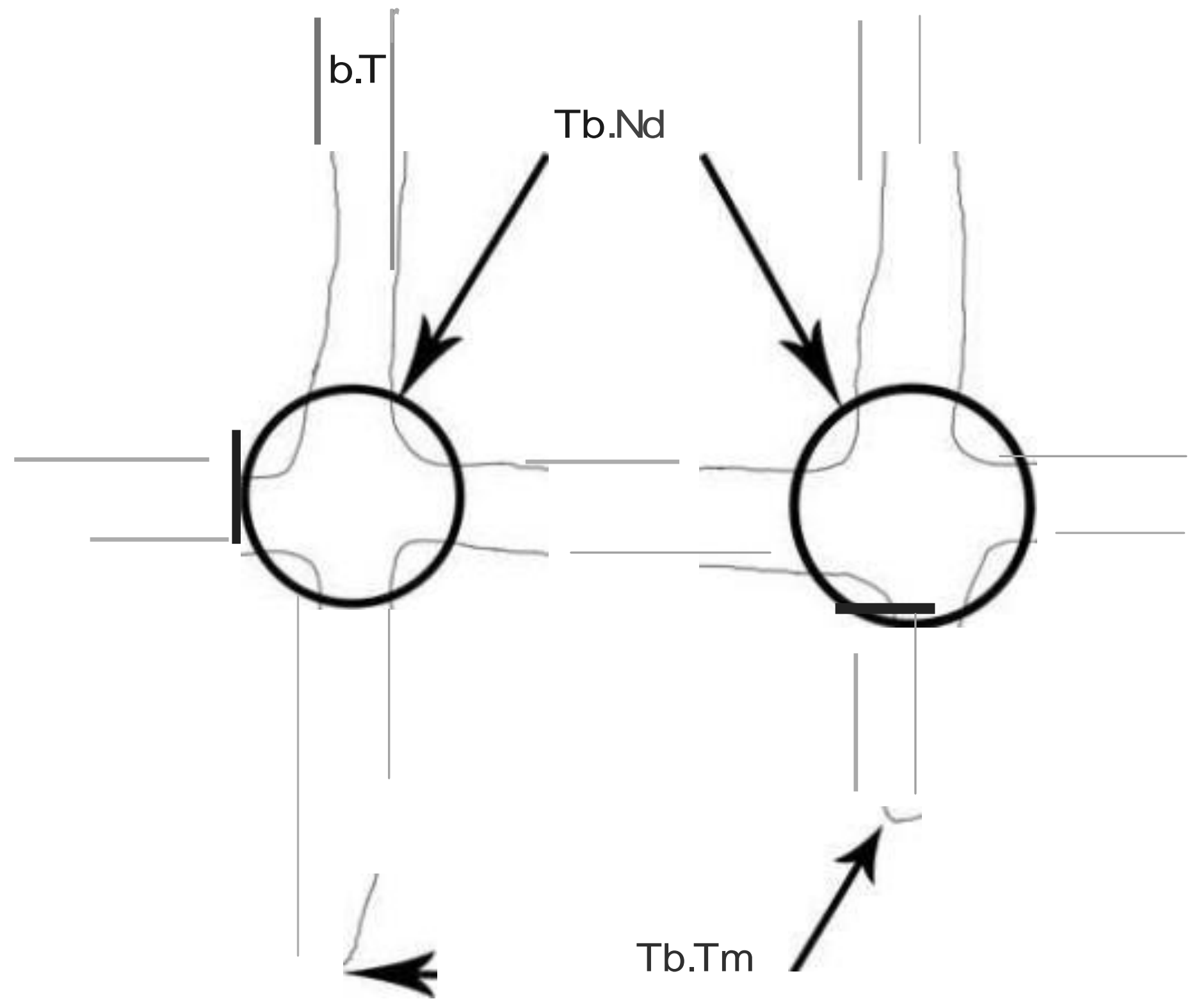




$$
\stackrel{\ominus}{\ominus}
$$



Figure_4

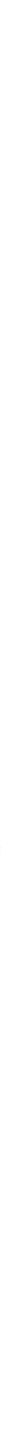


Figure_5

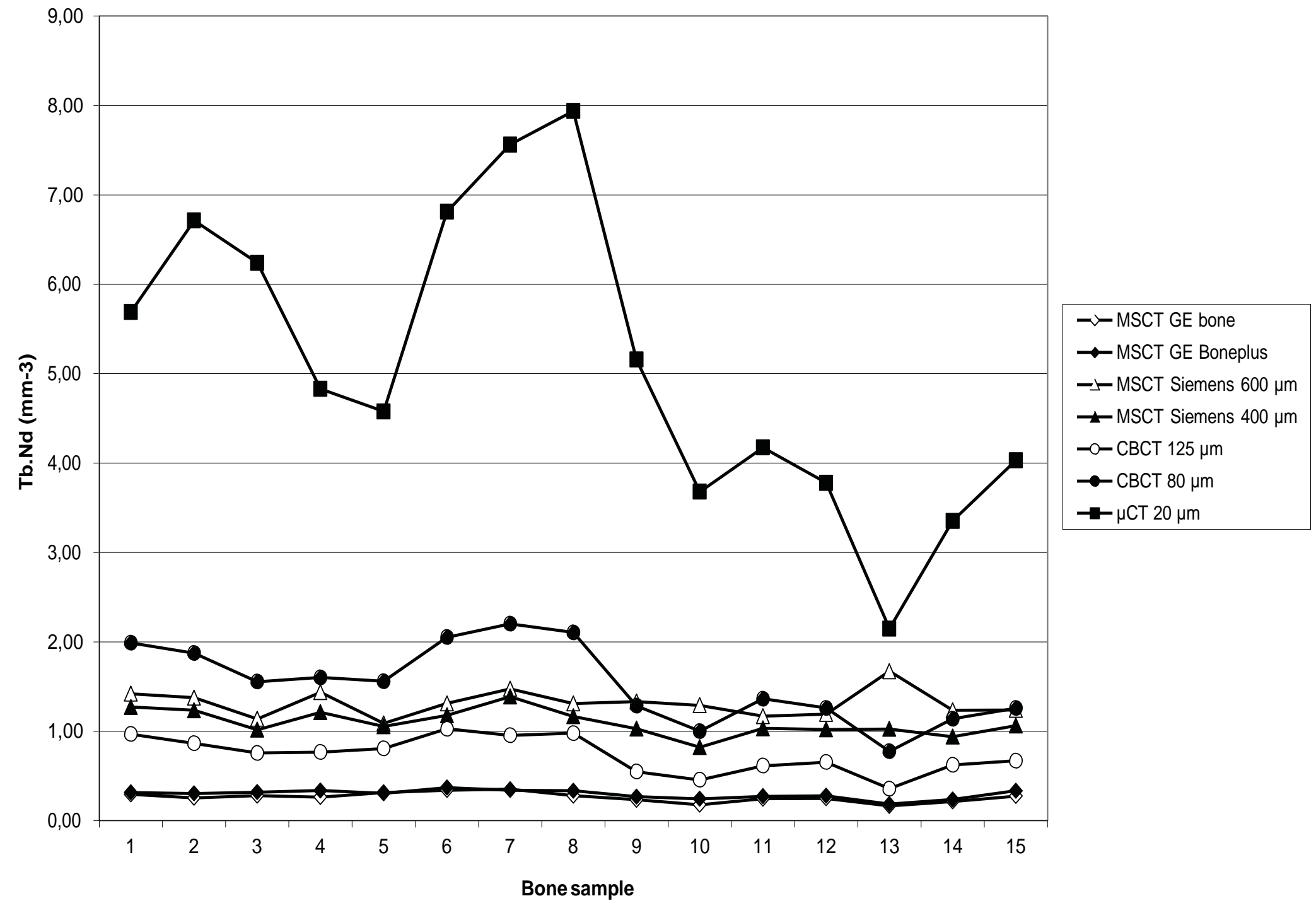


Figure_6

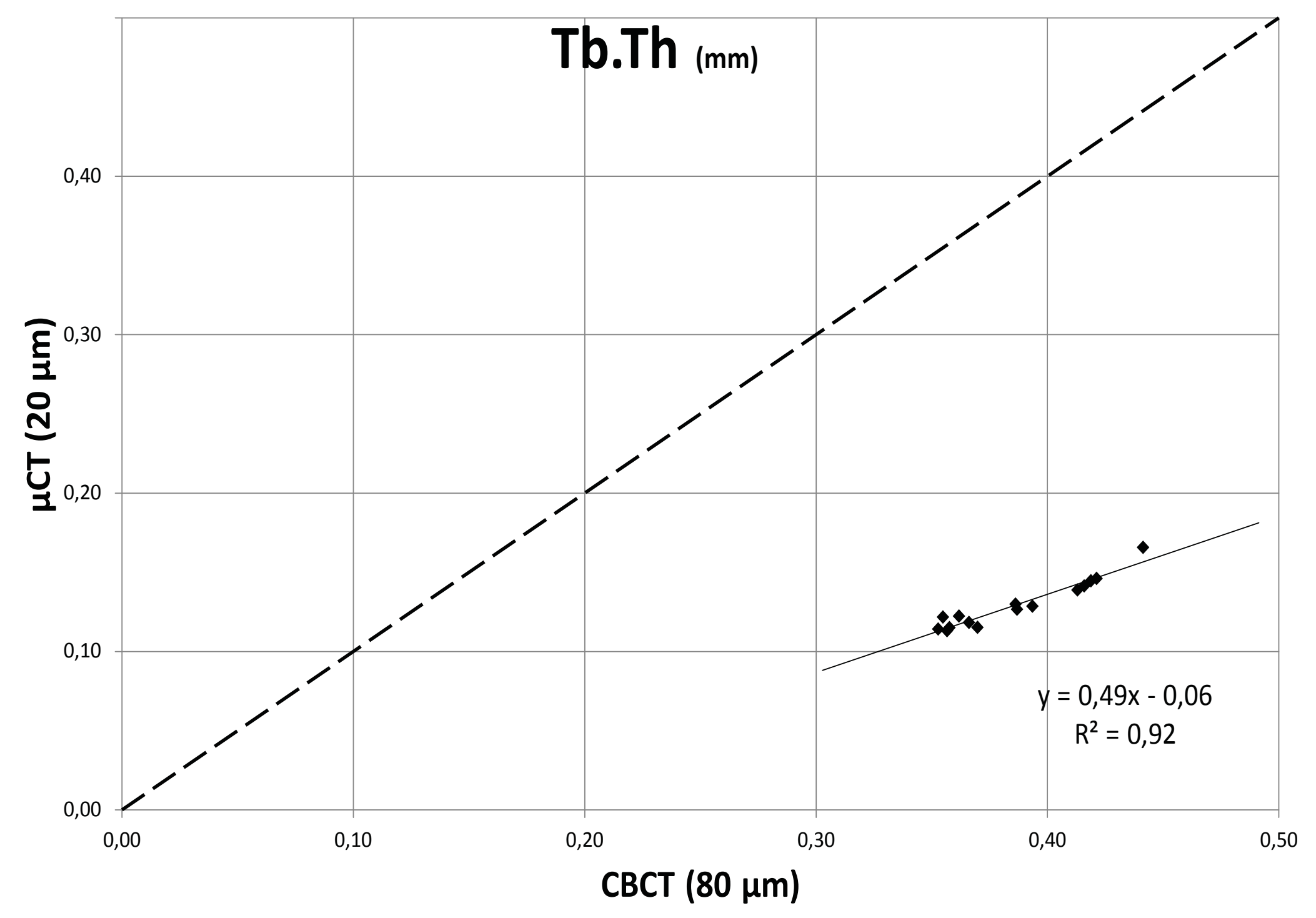


Figure_7

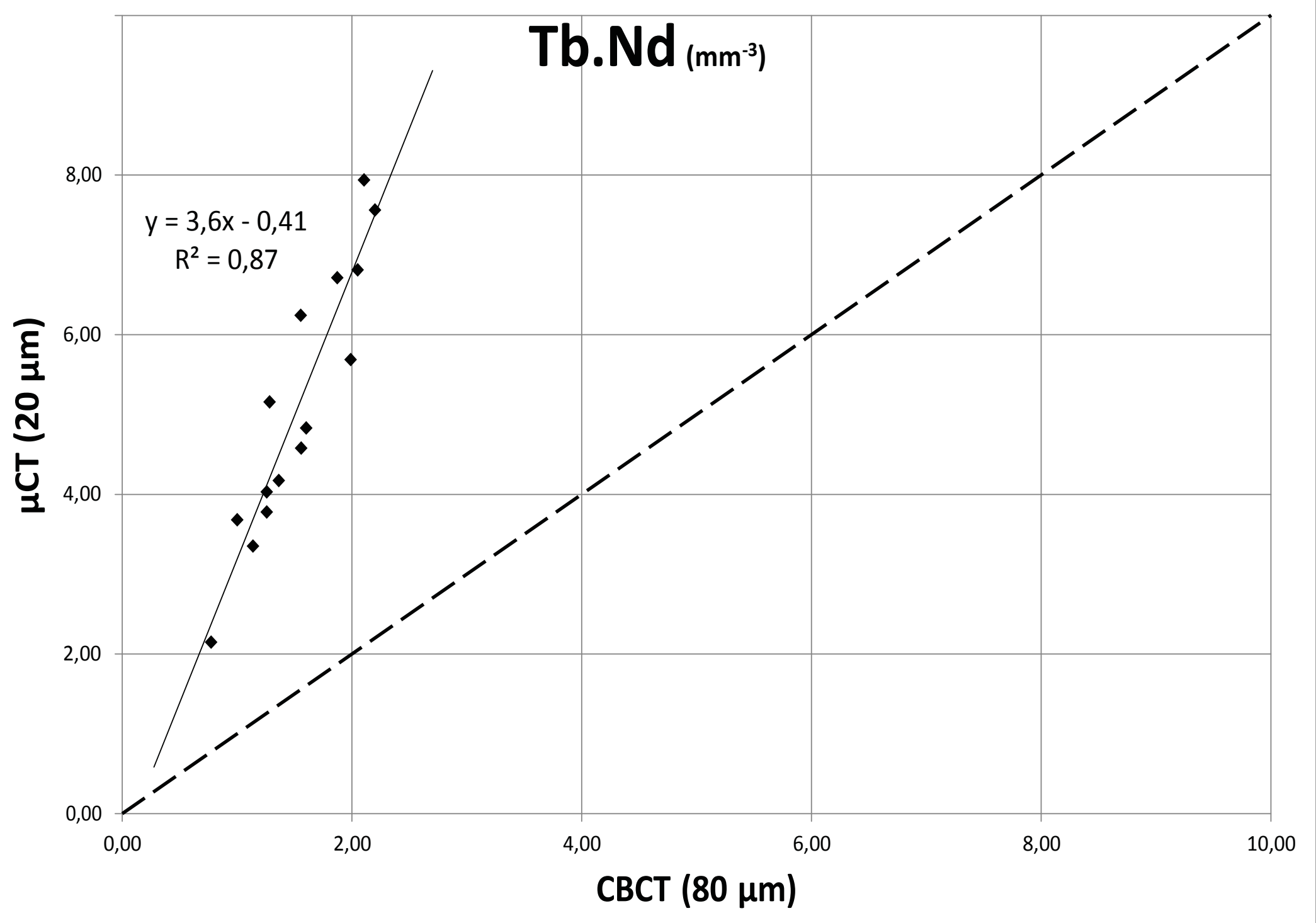


Fig. 1 Slices $(\mathbf{a}, \mathbf{b}, \mathbf{c})$ and volume renderings $(\mathbf{d}, \mathbf{e}, \mathbf{f})$ of acquired images from multi-slice CT $(\mathbf{a}, \mathbf{d})$, cone-beam CT $(\mathbf{b}, \mathbf{e})$ and micro-CT $(\mathbf{c}, \mathbf{f})$

Fig. 2 Segmentation result from micro-CT data, slice (a) and volume rendering (b)

Fig. 3 Description of trabecular bone structure parameters: volume fraction (BV/TV) (a); trabecular thickness (Tb.Th) and trabecular nodes (Tb-Nd) (b); trabecular spacing (Tb.Sp) and trabecular number (Tb.N) (c)

Fig. 4 Trabecular thickness of the 15 different bone samples measured from the different CT machines using the ARG segmentation algorithm

Fig. 5 Trabecular nodes of the 15 different bone samples measured from the different CT machines using the ARG segmentation algorithm

Fig. 6 Linear regression analysis of trabecular thickness $[\mathrm{mm}]$ measured from cone-beam CT $(80 \mu \mathrm{m})$ and micro-CT $(20 \mu \mathrm{m})$

Fig. 7 Linear regression analysis of trabecular nodes $\left[\mathrm{mm}^{-3}\right]$ measured from cone-beam CT $(80 \mu \mathrm{m})$ and micro-CT $(20 \mu \mathrm{m})$ 